\author{
VERÓNICA RAMírez ERRÁZURIZ* \\ Patricio Leyton Alvarado*
}

\title{
El RASTRO DEL COMETA HALley: \\ Circulación y legitimación del saber astronómico en Chile
}

$(1910)^{1}$

\begin{abstract}
RESUMEN
Este trabajo describe cómo circularon, en el ámbito local y global, algunas hipótesis sobre el cometa Halley de 1910, y cómo estas afectaron en el proceso de legitimación de expertos en materia astronómica y en el desarrollado de públicos de la ciencia en Chile. Asimismo, el artículo demuestra que la movilidad de estos conocimientos se produjo a través del despliegue de un mercado editorial dedicado al fenómeno celeste en el periodo. La perspectiva teórica desde la que se aborda esta problemática considera a la historia de la ciencia y se concentra, en la relevancia de las audiencias, por lo que las fuentes de este estudio consisten en dispositivos impresos publicados en Chile durante esos años, sobre todo proyectos periodísticos de amplia cobertura y distribución que, gracias a la modernización de la industria editorial, comenzaron a circular a inicios del siglo XX.
\end{abstract}

Palabras claves: Chile, siglo XX, Astronomía, circulación del conocimiento, legitimación de expertos, cometa Halley.

\section{AbSTRACT}

This article describes how theories related to the passage of Halley's Comet in 1910 circulated at a local and global level, and how they affected the legitimization process of astronomical experts and the development of scientific audiences in Chile. Likewise, this article demonstrates that the transit of this knowledge was produced through the deployment of an editorial market during this period that was dedicated to the celestial phenomenon. This article's theoretical perspective considers the history of science and focuses mainly on the public's relevance, so the sources of this study consist of printed texts published in Chile during these years, especially journalistic projects of wide coverage and distribution, that thanks to the modernization of the publishing industry began circulating in the early twentieth century.

\footnotetext{
* Doctora en Literatura, Universidad de Chile. Académica e investigadora de la Facultad de Artes Liberales, Universidad Adolfo Ibáñez. Correo electrónico: vramirez@uai.cl

** Licenciado en Historia, Pontificia Universidad Católica de Chile. Correo electrónico: hpleyton@uc.cl

${ }^{1}$ Este trabajo se enmarca en el desarrollo del proyecto de investigación Fondecyt n. ${ }^{\circ} 3180131$.
} 
KEYwORDs: Chile, twentieth century, astronomy, knowledge in transit, legitimation of experts, Halley's Comet.

Recibido: Enero 2020.

Aceptado: Agosto 2020.

\section{INTRODUCCIÓN}

El paso de los cometas en la historia de la humanidad ha estado vinculado a una serie de creencias populares que relacionan a estos cuerpos celestes con plagas, sequías, inundaciones, señales divinas y revueltas sociales. Estas suposiciones, como ha argumentado Sara Schechner, son parte de la cultura popular desarrollada por las sociedades, la cual se ha manifestado mediante efemérides, almanaques, baladas, juegos, pinturas, sermones, xilografías y grabados. Estos registros dan cuenta de las diversas actitudes que asumieron sobre los cometas distintas audiencias, las que, a su vez, crearon diferentes formas de apropiación vinculadas al folclore local y a la cultura erudita ${ }^{2}$.

Uno de los cometas que ha causado gran fascinación y curiosidad en distintas épocas de la historia es el cometa Halley, que debe su nombre al astrónomo de origen inglés Edmund Halley, quien logró determinar la órbita de este astro en 1682 mediante la utilización de la teoría de la gravitación universal de Isaac Newton, afirmando que aquel era el mismo que fue visto en 1531 y 1607 , y pronosticando que volvería a ser visible en $1758^{3}$. Pero las observaciones de Edmund Halley y las publicaciones de otros científicos sobre este tipo de fenómenos no fueron suficientes para que las audiencias dejaran de lado sus creencias. Estas se mantuvieron, sobre todo respecto al cometa Halley, el cual había transitado en momentos claves de la humanidad, coincidiendo con la muerte de reyes, inicio de guerras y propagación de enfermedades, ligándose con augurios del fin de los tiempos ${ }^{4}$. Uno de los pasos del cometa aludido que generó mayor controversia fue el del año 1910, debido a que algunos astrónomos, entre ellos el francés Camille Flammarion, predijeron una supuesta colisión de la cola del astro con la atmósfera terrestre, lo que causaría una serie de catástrofes que podían terminar con la vida en la faz de la Tierra. Para algunos países latinoamericanos este evento astronómico coincidió con la celebración del centenario de la Independencia, produciendo gran expectación en la prensa y temor en las personas 5 .

\footnotetext{
2 Sara Schechner, Comets, Popular Culture, and the Birth of Modern Cosmology, Princeton, Princeton University Press, 1997, p. 12.

${ }^{3}$ Donald Yeomans, Comets. A Chronological History of Observation, Science, Myth, and Folklore, New York, Wiley Science Editions, 1991, p. 112.

${ }^{4}$ Sobre el cometa Halley y la importancia de sus apariciones históricas, véase Isaac Asimov, Guide to Halley's Comet, New York, Walker \& Company, 1985.

${ }^{5}$ La historiografía chilena referida a la celebración del centenario de la República le ha dado muy poca importancia a las predicciones sobre el Halley y su vínculo con los públicos, remitiéndose tan solo a indicar que generó miedo y terror en algunos sectores de la población. Al respecto, consúltese Bernardo Subercaseaux, Historia de las ideas y de la cultura en Chile. Tomo III: El centenario y las vanguardias, Santiago, Editorial Universitaria, 2004, p. 40; Soledad Reyes, Chile en 1910. Una mirada cultural de su Centenario, Santiago, Editorial Sudamericana, 2004, p. 274.
} 
A pesar de la importancia que le brindaron las audiencias sudamericanas al paso del cometa Halley en 1910, son pocos los estudios históricos que han analizado de manera específica su cobertura en la prensa chilena y la circulación del saber en torno al astro en ese marco $^{6}$. Incluso, de parte de la historiografía de la astronomía nacional, ha recibido muy poca atención este cuerpo celeste 7 . El trabajo de Andrés Baeza titulado "Chile en 1910: el Centenario de la muerte" es el que ha abordado de manera más completa esta temática. Sin embargo, su análisis se concentra en la historia de las mentalidades y en las implicancias socio-políticas que acompañaron a este astro, dejando abiertas muchas otras aristas por las cuales estudiar el paso del Halley en el contexto chileno ${ }^{8}$. Nuestro artículo aborda esta problemática desde la perspectiva de la historia de la ciencia, y se

\footnotetext{
${ }^{6}$ Sobre los estudios históricos que abordan el paso del cometa Halley en 1910 en los contextos iberoamericanos, consúltese para el caso de Portugal el trabajo de Ana Simoes, Isabel Zilhao, María Paula Diogo and Ana Carneiro, "Halley turns republican: how the portuguese press presented the 1910 return of Halley's comet”, in History of Science, vol. 51, No. 2, New York, 2013, pp. 199-220. En España uno de los trabajos más completos es el de Pedro Ruiz-Castell, Ignacio Suay-Matallana y Juan Marcos Bonet, "El cometa de Halley y la imagen pública de la astronomía en la prensa diaria española de principios del siglo XX”, en Dynamis, vol. 33, n. ${ }^{\circ}$ 1, Granada, 2013, pp. 169-193, quienes estudian el paso de cometa y su registro por la prensa diaria destacando el papel mediador de los periódicos y la formación de un público de lectores. En España también se ha estudiado a los divulgadores que difundieron este fenómeno astronómico, tales como: Josep Comas i Solà, véase Ignasi Cebrian i Ester, "Josep Comas i Solà: Divulgador científico", en Quark, n. " 26, Barcelona, 2002, pp. 1-9 y José M. Meliá Bernabéu, en Pedro Ruiz-Castell, “José M. Meliá Bernabéu, 'Pigmalión’ y la divulgación de la astronomía en la Valencia de la primera mitad del siglo XX", en Dynamis, vol. 37, n. ${ }^{\circ}$ 2, Granada, 2017, pp. 435-457. En América Latina encontramos algunos trabajos publicados en esta misma línea. Entre ellos, el de Márcio Miranda Alves, "Do teatro ao cometa: contribuçoes da revista L'Illustration para á estética de $O$ Retrato", em Revista de Letras, vol. 52, n. ${ }^{\circ}$, São Paulo, 2012, pp. 73-93, quien ha estudiado cómo fue abordado este cometa en las revistas brasileras a través del proceso de ilustración. En Costa Rica destacan los artículos de Ronald Díaz Bolaños, "Los costarricenses no han dejado de admirar las magnificencias del cielo: la evolución de las ideas astronómicas en Costa Rica (1814-1910)", en Diálogos. Revista Electrónica de Historia, vol. 6, n. ${ }^{\circ}$ 1, San José, 2005, pp. 282-307; Roland Díaz Bolaños, Flora Solano Chaves y Mario Fernández Arce, "Los fenómenos celestes en Costa Rica: aerolitos, bólidos y lluvias de estrellas (1799-1910)", en Revista Geológica de América Central, n. ${ }^{\circ}$ 36, San José, 2007, pp. 97-114. En Argentina, Edgardo Minniti y Santiago Paolantonio, Córdoba estelar: desde los sueños a la astrofísica. Historia del Observatorio Nacional Argentino, Córdoba, Editorial Universidad Nacional de Córdoba, 2008, pp. 347-364, han estudiado la observación del Halley realizada por el Observatorio Astronómico Nacional de Córdoba y su vinculación internacional. En Chile, en tanto, el cometa no ha sido plenamente estudiado, tan solo se le hace alguna mención en algunas publicaciones que tratan sobre el centenario de la República.

${ }^{7}$ Rómulo Grandón, "El Observatorio Astronómico Nacional: reseña de su desarrollo y actividades en sus primeros cien años de existencia”, en Anuario del Observatorio Astronómico Nacional de la Universidad de Chile, Santiago, 1952, pp. 7-35; Arturo Aldunate, Chile mira hacia las estrellas: pequeña historia astronómica, Santiago, Editora Nacional Gabriela Mistral, 1975; Hugo Moreno, "Historia de la astronomía en Chile", en Héctor Álvarez y Hugo Moreno (eds.), Astronomía básica para profesores, Santiago, Centro de Perfeccionamiento, Experimentación e Investigaciones Pedagógicas, 1980, pp. 1-24; Philip Keenan, Sonia Pinto y Héctor Álvarez, El Observatorio Astronómico Nacional (1852-1965), Santiago, Universidad de Chile, Facultad de Ciencias Físicas y Matemáticas, 1985; Miguel González, "Primeros observatorios astronómicos en América: sesquicentenario del Observatorio Astronómico de Santiago de Chile, 1852-2002", en Actas del Tercer Congreso Nacional de Astronomía de Antofagasta, Antofagasta, Universidad Católica del Norte, Instituto de Astronomía, 2002, pp. 1-17; Hernán Quintana y Augusto Salinas, "Cuatro siglos de astronomía en Chile", en Revista Universitaria, n. ${ }^{\circ}$ 83, Santiago, 2004, pp. 53-60; Edgardo Minniti y Santiago Paolantonio, "Observaciones de la latitud sur de la América remota", en Saber y Tiempo, n. ${ }^{\circ}$ 19, Buenos Aires, 2006, pp. 113-125.

${ }^{8}$ Andrés Baeza, "Chile en 1910: el Centenario de la muerte", en Andrés Baeza et al., XX: Historias del siglo veinte chileno, Santiago, Ediciones B, 2008, pp. 19-80.
} 
concentra en la relación entre la ciencia y sus públicos, los que serán entendidos como un conjunto de actores que involucran a los productores y receptores del conocimiento que participan en el proceso de consolidación de la autoridad científica y de legitimación de los distintos saberes. En este sentido, el concepto "público de la ciencia" incorpora a diferentes grupos sociales, tales como: espectadores, visitantes, usuarios, editores, redactores, traductores, lectores, divulgadores y los mismos científicos; lo que hace de la categoría "público de la ciencia" una condición cambiante y flexible?. En este trabajo se pone especial énfasis en los públicos compuestos por los periódicos chilenos y por los científicos locales.

Para ello hemos consultado diversas fuentes impresas a través de las cuales se movilizó el conocimiento astronómico en el territorio durante la primera década del siglo $\mathrm{XX}$, tales como la prensa diaria, revistas culturales, revistas científicas, conferencias impresas, libros e ilustraciones, entre otras. Nos hemos detenido especialmente en medios periodísticos, por su amplia cobertura y rápida distribución, características que adquirieron estos proyectos gracias al proceso de modernización de la industria editorial acontecido en esos mismos años. La modernización de los medios de prensa se manifestó mediante la paulatina transformación de los periódicos en verdaderas empresas comerciales que privilegiaron las noticias informativas por sobre las de tipo partidista o ideológica, con el propósito de buscar un mercado más amplio de lectores ${ }^{10}$. De esta forma, los periódicos fueron los medios escritos que tuvieron mayor relevancia al momento de transmitir los saberes científicos a la población, debido a que eran más económicos en comparación con los libros y eran de mayor acceso por parte de los lectores gracias a sus formas de distribución. Además, los diarios incluyeron en sus páginas una mayor variedad de temáticas científicas en comparación con los libros, y su lenguaje estaba dirigido hacia un público lego, no especializado ${ }^{11}$. Por lo cual, la comunicación de los saberes científicos a través de la prensa facilitó -y continúa facilitando- la comprensión del papel de la ciencia por parte de la sociedad, así como la democratización del conocimiento en la ciudadanía, contribuyendo a la educación científica de las personas ${ }^{12}$.

\footnotetext{
${ }^{9}$ Agustí Nieto-Galan, Los públicos de la ciencia. Expertos y profanos a través de la historia, Madrid, Marcial Pons, 2011, pp. 15-16.

${ }^{10}$ Stefan Rinke, Cultura de masas: reforma y nacionalismo en Chile 1910-1931, Santiago, Ediciones de la Dirección de Bibliotecas, Archivos y Museos, Centro de Investigaciones Diego Barros Arana, 2002, p. 40; Carlos Ossandón y Eduardo Santa Cruz, El estallido de las formas: Chile en los albores de la "cultura de masa”, Santiago, LOM Ediciones / Universidad ARCIS, 2005, pp. 134-145; Eduardo Santa Cruz, Prensa y sociedad en Chile, siglo XX, Santiago, Editorial Universitaria, 2015, pp. 24-25.

${ }^{11}$ Bernard Lightman, Victorian Popularizers of Science. Designing Nature for New Audiences, Chicago \& London, The Chicago University Press, 2007, pp. 13-17; Aileen Fyfe, "Journal and Periodicals", in Bernard Lightman (ed.), A Companion to the History of Science, Oxford, John Wiley \& Sons Ltd., 2016, pp. 387-399.

${ }^{12}$ Gitte Meyer, The Science Communication Challenge. Truth and Disagreement in Democratic Knowledge Societies, New York, Anthem Press, 2018, pp. 1-3. En los últimos años la prensa ha sido una fuente muy valorada en el área de la historia de la ciencia en Chile, publicándose varios estudios que analizan el papel de los periódicos en la conformación de públicos y en la circulación de los saberes científicos. Dentro de esta mirada, la astronomía ha recibido un particular interés de parte de las investigadoras y los investigadores nacionales. Sobre los diarios y la publicación de noticias astronómicas en Chile en el siglo XIX, véase: Silvia Becerra y Zenobio Saldivia, El Mercurio de Valparaíso, su rol de difusión de la ciencia y tecnología en el Chile decimonónico, Santiago, Bravo y Allende Editores, 2010; Lorena Valderrama, "La ca-
} 
Los periódicos que cubrieron el tránsito del Halley empleados en este artículo corresponden a proyectos de las ciudades de Antofagasta, Valparaíso, Santiago y Concepción, que eran las urbes más pobladas y que poseían una mayor relevancia política, comercial y cultural en relación con otras ciudades del país, así como una tradición periodística más longeva. Para el caso de Antofagasta - principal puerto salitrero del norte de Chile- se utilizó el diario El Industrial (1881-1938), fundado por el ingeniero Matías Rojas Delgado en 1881, el cual se caracterizó por poseer un gran formato, excelente calidad periodística y una buena impresión, manteniendo por varios años altos estándares de información noticiosa a pesar de los cambios de propietario ${ }^{13}$. Este diario se convirtió al comienzo del siglo XX en el principal medio informativo del norte del país, alcanzando una circulación cercana a los seis mil ejemplares ${ }^{14}$. Para Valparaíso -ciudad portuaria, comercial y cosmopolita- se revisó El Mercurio de Valparaíso (1827-hasta hoy), fundado en 1827 y transformado en el diario más importante de la ciudad-puerto al ser adquirido por la familia Edwards en la década de $1880^{15}$. Gracias al modelo empresarial que le inculcó Agustín Edwards Mac Clure, tanto a este periódico como a los otros medios comunicacionales que fundó, basado en la inversión de nuevas tecnologías de impresión y la aplicación de estrategias eficientes de ventas y distribución, como ocurrió con El Mercurio de Santiago ${ }^{16}$, su empresa se consolidó a escala nacional como líder en el rubro.

Para el caso de Concepción - urbe del centro-sur de Chile de mayor importancia en cuanto a población y producción industrial- se ha atendido el periódico El Sur (1882hasta hoy) que se transformó en el principal medio informativo penquista hacia fines del siglo XIX, tras ser fundado por el político radical Juan Castellón Acuña en 1882. El propósito de este periódico era convertirse en un medio que fuera más allá de la contingencia política, identificándose con las problemáticas de Concepción y sus zonas aledañas, lo que llevó a darle preponderancia a los intereses informativos de dicha comunidad y definirse como una publicación independiente. En 1901, El Sur inició un proceso de modernización a cargo de Aurelio Lamas Benavente, quien invirtió en nuevas tecnologías de impresión y capacitó a su personal para utilizar las nuevas maquinarias,

tástrofe anunciada: terremotos y predicciones en la prensa diaria chilena (1906-1912)”, en María José Correa, Andrea Kottow y Silvana Vetö (eds.), Ciencia y espectáculo, Circulación de saberes científicos en América Latina, Siglos XIX y XX, Santiago, Ocho Libros Editores, 2016, pp. 169-195; Verónica Ramírez y Patricio Leyton, "Andrés Bello y la difusión de la astronomía: educación y retórica científica", en Asclepio, vol. 69, n. ${ }^{\circ}$ 2, Madrid, 2017, pp. 1-14; Verónica Ramírez y Patricio Leyton, "José Victorino Lastarria: astronomía científica, literaria y social, en Dynamis, vol. 39, n. ${ }^{\circ}$ 1, Granada, 2019, pp. 123-147; Verónica Ramírez y Patricio Leyton, "El eclipse solar de 1867: ciencia, política y religión en el Chile republicano, en Historia 396, vol. 9, n. ${ }^{\circ}$, Viña del Mar, 2019, pp. 263-307; Verónica Ramírez y Patricio Leyton, "Benjamín Vicuña y la ciencia: defensor de la astronomía popular en Chile a fines del siglo XIX”, en Historia y Sociedad, n. ${ }^{\circ}$ 38, Medellín, 2020, pp. 71-102; Lorena Valderrama y Verónica Ramírez, Lo que auguran los astros. Espectáculos, maravillas y catástrofes en la prensa chilena (1868-1912), Santiago, RIL Editores, 2020.

${ }^{13}$ Isidoro Morales, La prensa en la historia de la Región de Antofagasta, Antofagasta, Corporación Pro Antofagasta, 2006, pp. 24-25.

${ }^{14}$ Rinke, op. cit., p. 41.

${ }^{15}$ Con la compra de los Edwards este periódico alcanzó, en las primeras décadas del siglo XX, un tiraje cercano a los treinta mil ejemplares: Rinke, op. cit., p. 41.

${ }^{16}$ Patricio Bernedo y Eduardo Arriagada, "Los inicios de El Mercurio de Santiago en el epistolario de Agustín Edwards Mac Clure”, en Historia, vol. 35, Santiago, 2002, pp. 13-33. 
aumentando el tiraje de forma significativa e introduciendo un formato de páginas más manejable ${ }^{17}$.

En la capital, en tanto, se concentraron los principales diarios del país, los cuales se instalaron en el área céntrica y comercial de Santiago, ocupando el barrio cívico de la ciudad y manteniendo una proximidad entre ellos ${ }^{18}$. Para el análisis se consideró El Diario Ilustrado (1902-1970) ${ }^{19}$, uno de los periódicos capitalinos que tuvo mayor preponderancia periodística en los primeros años del siglo XX, fue fundado en 1902 por Ricardo Salas Edwards, quien introdujo como innovación el fotografiado en reemplazo del sistema de litografiado, lo que facilitó la publicación de fotografías por primera vez en Chile, provocando una revolución en el periodismo nacional. Además, alcanzó los treinta mil ejemplares en $1908^{20}$, convirtiéndose en uno de los matutinos de mayor circulación en el país, junto con El Mercurio de Santiago.

La prensa diaria no fue el único tipo de medio escrito que informó a la población chilena sobre el paso del cometa Halley, ya que también fue cubierto por revistas culturales y magazines. Estos últimos, también conocidos como revistas ilustradas o de variedades, surgieron en Chile a inicios del siglo XX como respuesta a los cambios culturales y la diversificación de los públicos. Ellas fueron una manifestación del desarrollo de la industria editorial y la ampliación del mercado informativo, lo que se tradujo en la incorporación de nuevas tecnologías de impresión, facilitando la integración de fotografías, imágenes y colores. Estas innovaciones fueron claves en la conformación de este tipo de publicaciones ${ }^{21}$. Carlos Ossandón y Eduardo Santa Cruz han definido el magazine como "un periódico ilustrado, estructurado sobre la base de numerosas secciones y generalmente de muchas páginas y de aparición semanal o mensual" ${ }^{22}$. Una de las revistas revisadas para este trabajo es Sucesos (1902-1932), fundada por Alberto y Gustavo Helfmann en Valparaíso, cuyo objetivo principal fue ser un magazine de actualidad. Se caracterizó por no restringirse al ámbito exclusivo de la vida social, sino que amplió su oferta informativa a la vida cotidiana, el deporte, la política, la crónica policial, los adelantos tecnológicos y los descubrimientos científicos. En consecuencia, en su programa editorial tuvieron cabida diversos temas vinculados al progreso cultural del país ${ }^{23}$. Tuvo un público amplio y masivo, y no existió ninguna imposición que intentara segmentar a sus lectores, ni tampoco el propósito de difundir un ideario o transmitir una causa autoim-

\footnotetext{
${ }^{17}$ Fernando Casanueva, Prensa y periodismo en Concepción, 1833-2000, Concepción, Universidad de la Santísima Concepción / Escuela de Periodismo, 2002, pp. 253-264.

${ }_{18}$ Tomás Cornejo, Ciudad de voces impresas. Historia cultural de Santiago de Chile, 1880-1910, Santiago, Centro de Investigaciones Diego Barros Arana / El Colegio de México, 2019, p. 89.

${ }^{19}$ Hemos optado por El Diario Ilustrado por sobre El Mercurio de Santiago, debido a que utilizaremos la versión de Valparaíso del periódico perteneciente a la familia Edwards y El Ferrocarril, por su parte, se encontraba en un período de decadencia.

${ }^{20}$ Ossandón y Santa Cruz, op. cit., p. 163.

${ }^{21}$ Op. cit., p. 34; Santa Cruz, op. cit., p. 55; Cecilia García-Huidobro y Paula Escobar, Una historia de las revistas chilenas, Santiago, Ediciones Universidad Diego Portales, 2012, p. 21; Marina Alvarado, Revistas culturales y literarias chilenas de 1900 a 1920: legitimadoras del campo literario nacional, Santiago, Editorial Cuarto Propio, 2016, pp. 60-61.

${ }^{22}$ Ossandón y Santa Cruz, op. cit., p. 33.

${ }^{23}$ García-Huidobro y Escobar, op. cit., p. 27; Santa Cruz, op. cit., p. 60.
} 
puesta $^{24}$. En sus inicios, se centró en situaciones de la vida porteña, pero al poco tiempo comenzó a referirse a aspectos propios de la vida capitalina y del resto del mundo.

Otro de los magazines revisados en virtud de su relevancia en esta época, fue la revista Zig-Zag (1905-1964), creada por Agustín Edwards Mac Clure en 1905 tras viajar a Estados Unidos y observar este tipo de publicaciones en ese país. Esta revista contó con fuertes desafíos gráficos, incorporando los últimos adelantos en fotografía y grabado. Invirtió en una fuerte apuesta visual, comercial y publicitaria, lo que lo llevó a ser uno de los magazines más vendidos en el país, alcanzando en sus primeros años una circulación cercana a los cincuenta mil ejemplares. Su consumo trascendió a la élite, siendo un producto al que también tuvo acceso la clase media emergente. Se convirtió, además, en una plataforma en la que participaron distintos intelectuales chilenos, que publicaron columnas de opinión y artículos informativos ${ }^{25}$.

Un tercer magazine revisado fue Corre-Vuela (1908-1927), que también perteneció a la Editorial Zig-Zag, pero tuvo un carácter más popular que el anterior y con un precio menor: mientras revista Zig-Zag tenía un valor de cincuenta centavos, Corre-Vuela tenía un precio de veinte centavos ${ }^{26}$. Esta última se destinó a las clases populares, visibilizando la distancia existente entre las autoridades y las clases subalternas, cultivó un tono satírico, pero, a la vez, incorporó temáticas y formatos comunicacionales diversos, propios del género del magazine, destacando los comentarios políticos y notas de actualidad $^{27}$.

El tránsito del Halley por los cielos chilenos en 1910 arrastró consigo una serie de problemáticas complejas que rebasaron lo astronómico y que dificultan el análisis histórico del fenómeno. En ese sentido, creemos que el artículo de Andrés Baeza -al que ya hemos hecho referencia- se hizo cargo de manera efectiva del contexto sociopolítico chileno que enmarcó el acercamiento del cometa en dicho año, pero no consideró asuntos culturales relevantes que permitirían entender con mayor plenitud los alcances y significados de este acontecimiento desde una perspectiva histórica. Dentro de esos aspectos culturales resulta crucial la polémica científica ocasionada por el astro, tanto en el ámbito global como local, así como la activación de un mercado editorial local a raíz del portento astronómico, que impulsó el sostenimiento de periódicos, revistas y folletos, y dio cabida a dispositivos de variados géneros (artículos de divulgación, relatos de ciencia-ficción, caricaturas, publicidad, etc.). La importancia de estos dos elementos radica en que los intentos de legitimación de expertos locales, así como la consolidación de públicos de la ciencia en un territorio específico, pueden comprenderse en la medida en que se examina la interacción entre la predicción científica, en general, y la representación y uso que hace la sociedad de esa predicción científica, en particular; es decir, entre lo que plantean ciertos científicos sobre el Halley y los replanteamientos de los públicos de la ciencia (editores, redactores, otros científicos, lectores, etc.) sobre este, ambas posiciones presentes en los impresos señalados.

\footnotetext{
${ }^{24}$ Ossandón y Santa Cruz, op. cit., pp. 48-49.

${ }^{25}$ Op. cit., pp. 61-66; García-Huidobro y Escobar, op. cit., pp. 31-33; Alvarado, op. cit., pp. 120-126.

${ }^{26}$ García-Huidobro y Escobar, op. cit., p. 32.

${ }^{27}$ Ossandón y Santa Cruz, op. cit., pp. 103-104.
} 
Considerando lo expuesto, el trabajo fue estructurado en función de las siguientes preguntas: ¿Cómo circularon las teorías científicas sobre el cometa Halley dentro y fuera del territorio chileno? ¿En qué medida el tránsito de este saber astronómico generó una instancia propicia para la búsqueda de legitimación de expertos en Chile y para la ampliación de audiencias locales? ¿En qué sentido un fenómeno astronómico promovió un mercado editorial local?

Los expertos en Chile en materia astronómica estuvieron representados en la época por el personal científico del Observatorio Astronómico Nacional (OAN). Esta institución, gracias al apoyo político de parte del gobierno de Pedro Montt, entró en un proceso de reformulación y modernización liderado por el astrónomo alemán Friedrich Ristenpart, contratado por el Estado chileno en 1908. Este último inició una serie de reformas para revitalizar el establecimiento científico, las que tuvieron como principal preocupación el traslado de las instalaciones a una mejor ubicación, la obtención de instrumentos de observación modernos y la mejora del salario para el personal ${ }^{28}$. El paso del cometa Halley, observado por este director y sus colaboradores, se convirtió en una instancia para buscar la validación ante las autoridades políticas y la población chilena, utilizando como estrategia la aparición en los medios escritos que representaron la opinión pública a inicios del siglo XX. El OAN, bajo las administraciones anteriores de José Ignacio Vergara y Albert Obrecht, había entrado en decadencia, tanto en materia científica como en su utilidad social, siendo cuestionado por las autoridades políticas y algunos intelectuales ${ }^{29}$. Por lo tanto, el advenimiento del Halley y la atención que la sociedad puso en ello, se convirtió en un escenario propicio para que la administración de Friedrich Ristenpart pudiera demostrar los cambios que había introducido, así como dar a conocer otras iniciativas que esperaba implementar.

De esta forma, el interés de la opinión pública centró su foco en la astronomía y, a través de ella, en el OAN. La preocupación despertada por algunas predicciones que definieron al Halley como un astro peligroso a escala global, justificó la aparición del director del OAN en los medios escritos e informativos para desmentir estas noticias argumentando con observaciones y cálculos propios, lo que se tradujo en una oportunidad para legitimarse socialmente como una voz autorizada frente a las audiencias y para ratificar también la producción de conocimiento local. Tal como han propuesto los autores Adi Ophir, Steven Shapin y Jan Golinski, las instituciones científicas -o también llamadas lugares del conocimiento- necesitan de la esfera pública para ser reconocidas por la sociedad y así validar sus prácticas ${ }^{30}$, y esto fue precisamente lo que intentó poner en práctica Friedrich Ristenpart durante el avistamiento del Halley en 1910.

\footnotetext{
${ }^{28}$ Grandón, op. cit., pp. 19-21; Aldunate, op. cit., pp. 136-137; Moreno, op. cit., p. 6; Keenan, Pinto y Álvarez, op. cit., p. 130; González, op. cit., pp. 9-11; Minniti y Paolantonio, op. cit., p. 117.

${ }^{29}$ Ramírez y Leyton, Benjamín Vicuña Mackenna..., op. cit., pp. 71-102; Carlos Sanhueza et al., "Todos los instrumentos están en buen estado. Disputas en torno al funcionamiento de los telescopios del Observatorio Astronómico Nacional de Chile en el siglo XIX”, en Asclepio, vol. 72, n. ${ }^{\circ}$ 1, Madrid, 2020, pp. 1-11.

${ }^{30}$ Adi Ophir \& Steven Shapin, "The place of knowledge a methodological survey", in Science in context, vol. 4, No. 1, Cambridge, 1991, pp. 3-21; Jan Golinski, Making natural knowledge: Constructivism and the History of Science, Cambridge, Cambridge University Press, 1998, pp. 79-102.
} 


\section{Algunas aClaraciones teóRICAS, METODOLÓGICAS Y CONCEPTUALES}

Para responder las preguntas planteadas en el apartado anterior, se siguen las propuestas metodológicas que han sugerido historiadores de la ciencia, tales como James Secord, quien a través de su concepto de knowledge in transit, propone entender la ciencia como un proceso comunicativo per se, de tal modo que la generación de conocimiento científico es, a su vez, un acto comunicativo, por lo que no tendría sentido separar la producción del saber, de la transmisión de este ${ }^{31}$. Esta manera de visualizar la circulación del conocimiento científico permite integrar dentro del proceso de generación del saber a las mismas audiencias, compuestas, como ya se ha señalado, por otros científicos, así como por los editores, redactores, conferencistas, receptores, etc., de diversos medios e instancias informativas. El conocimiento científico, en consecuencia, se define como el fruto no solo de prácticas académicas, sino, también, de la producción y reproducción del conocimiento alejado de los entornos académicos tradicionales ${ }^{32}$. Esta misma idea ha sido desarrollada por Agustí Nieto-Galan para contextos periféricos, apelando a la necesidad del "estudio de la permanente negociación entre expertos y profanos, más allá de las paredes de las instituciones de los primeros y más cerca de la esfera pública, popular y a menudo urbana de los segundos"33.

Pedro Ruiz-Castell, Ignacio Suay-Matallana y Juan Marcos Bonet enfatizan en este mismo sentido, enfocándose en la interpretación de la ciencia realizada en una cierta comunidad a propósito del paso del cometa Halley de 1910 en el contexto español ${ }^{34}$. Por otra parte, Ana Simoes, junto a Isabel Zilhao, María Paula Diogo y Ana Carneiro realizan un análisis similar para el contexto portugués ${ }^{35}$. Lorena Valderrama, asimismo, ha aplicado este enfoque para el caso de teorías sísmicas en Chile a fines del siglo XIX y principios del XX, analizando las formas de validación pública de estos saberes mediante la utilización de las audiencias ${ }^{36}$. La orientación de estos últimos trabajos ha inspirado en gran medida nuestro artículo.

Además de las propuestas teóricas anteriores, es preciso dialogar con el concepto de 'controversia' o 'disputa científica' definida por Gideon Freudenthal, ya que gran parte del problema a tratar se sustenta en la desavenencia entre astrónomos acerca de las características y particularidades del cometa Halley, y cómo esta discrepancia rebasó los límites científicos y acaparó la atención de las audiencias, estimulando la cobertura de este fenómeno en la prensa y en otros medios ${ }^{37}$.

\footnotetext{
${ }^{31}$ James Secord, "Knowledge in transit", in Isis, vol. 95, No. 4, Chicago, 2004, pp. 654-672.

${ }^{32}$ Jürger Renn, "From the History of Science to the History of Knowledge - and Back", in Centaurus, vol. 57 , New York, 2015, p. 38.

${ }^{33}$ Agustí Nieto-Galan, "Prólogo", en Correa, Kottow y Vetö (eds.), op. cit., p. 10.

${ }^{34}$ Ruiz-Castell, Suay-Matallana y Bonet, op. cit., p. 170.

${ }^{35}$ Simoes, Zilhao, Diogo y Carneiro, op. cit., pp. 199-220.

${ }^{36}$ Lorena Valderrama, Observando la catástrofe: terremotos y conocimiento sísmico en Chile (1868-1912), tesis para optar al grado de Doctora en Historia de la Ciencia y Comunicación Científica, Valencia, Universidad de Valencia, 2017.

${ }^{37}$ Gideon Freudenthal, "Controversy”, in Science in Context, vol. 11, No. 2, Cambridge, 1998, pp. 155-160.
} 
Por último, se discute con los trabajos de Aileen Fyfe y Bernard Lightman así como con el de Agustí Nieto-Galan, quienes también se refieren al trato de lo científico como negocio y mercancía ${ }^{38}$, y como una situación que era común en la época estudiada, debido a que las audiencias comenzaron a verse a sí mismas como consumidoras de libros, de museos y de distintas prácticas científicas antes y durante dicho periodo ${ }^{39}$. El mercado en torno a la actividad científica se consolidó durante el siglo XIX, bajo el rótulo de "ciencia popular", la que consistía en acercar los saberes a públicos variados mediante la publicación de libros, revistas y folletos con un lenguaje accesible a los lectores y con precios diferenciados según la condición socioeconómica o a través de la realización de conferencias, exhibiciones y ferias que mostraron los avances de la ciencia a los asistentes ${ }^{40}$. Por lo que, si bien el cometa Halley fue explotado de las más diversas maneras como un producto comercial, destacándose por sobre otros fenómenos científicos en el periodo, el hecho, por una parte, de que la ciencia ya fuese asociada al concepto de mercancía y, por otra, que la prensa aplicara este tipo de estrategias (sacar provecho de cualquier tipo de noticias, fenómenos, eventos, etc.) para vender y captar lectores, ayudaron para que se desarrollara un relevante mercado editorial específico en torno al Halley durante la primera década del siglo XX.

\section{El Halley COMO Un ESCENARIO de OPORTUNidAdES PARA ASTRÓNOMOS LOCALES}

Las disputas científicas generan escenarios propicios para que los implicados se legitimen como expertos en la materia de discusión. Tal como señala Pedro Ruiz-Castell, estas controversias deben entenderse como estrategias para obtener prestigio, legitimación y poder en momentos críticos ${ }^{41}$. Las diferencias entre científicos, entendidas desde dicho propósito de legitimación, involucran necesariamente a la sociedad, ya que para demostrar autoridad en la materia se debe persuadir no solo a la comunidad de expertos, sino, también, al público general ${ }^{42}$. Por lo tanto, las desavenencias científicas se convierten naturalmente en fenómenos sociales, como explica Alan Gross, puesto que la disputa de la prioridad en la autoría de un descubrimiento científico, por ejemplo, requiere del

\footnotetext{
${ }^{38}$ Nieto-Galan, Los públicos de la ciencia..., op. cit., p. 66.

${ }^{39}$ Aileen Fyfe \& Bernard Lightman, "Science in the Marketplace. An Introduction", in Aileen Fyfe \& Bernard Lightman (eds.), Science in the Marketplace. Nineteenth-Century Sites and Experiences, London, University of Chicago Press, 2007, p. 4.

${ }^{40}$ La ciencia popular ha adquirido un particular interés de parte de la historiografía en los últimos años, centrando su atención en cómo se fue configurando un mercado a partir de los saberes científicos y cómo las audiencias consumen este tipo de mercancías. Sobre el concepto de "ciencia popular" y sus problemáticas historiográficas, véase Jonathan Topham, "Rethinking the History of Science Popularitation/Popular Science", in Faidra Papanelopoulou, Agustí Nieto-Galan \& Enrique Perdiguero, Popularizing Science and Technology in the European Periphery, 1800-2000, Surrey, Ashgate, 2009, pp. 1-20.

${ }^{41}$ Pedro Ruiz-Castell, "Priority claims and public disputes in astronomy: E. M. Antoniadi, J. Comas I Solà and the search for authority and social prestige in the early twentieth century", in The British Journal for the History of Science, vol. 44, No. 4, Cambridge, 2011, p. 510.

${ }^{42}$ Op. cit., p. 531.
} 
involucramiento de testigos o de otros seres que den fe de lo que se defiende. De allí que los descubrimientos científicos sean actos sociales ${ }^{43}$. Los fenómenos astronómicos que despiertan el interés social por su evidente y fácil observación -como un eclipse o el acercamiento de un cometa- son situaciones que propician contextos idóneos para generar polémicas y, por ende, para promover la legitimación de expertos en la materia.

Durante el paso del cometa Halley en 1910 las disputas se centraron en la posible interacción de la cola del astro con la atmósfera terrestre. El francés Camille Flammarion, al promover esta hipótesis, se convirtió en uno de los astrónomos mayormente interpelado por los científicos que se oponían a esta posibilidad ${ }^{44}$. A través de su estilo divulgativo particular, popularizó la eventualidad de que la cola del cometa interaccionara con la atmósfera terrestre ocasionando la muerte de la humanidad debido a sus gases altamente tóxicos ${ }^{45}$. Gran parte de las referencias a asuntos astronómicos en las revistas y periódicos de principios del siglo XX se vincularon a este fenómeno y, en el caso de los medios chilenos, la mayoría de las colaboraciones correspondieron a traducciones de los textos del científico y divulgador francés, lo que despertó la reacción y oposición de astrónomos locales.

No se puede afirmar, sin embargo, que hubo entre estos últimos y Camille Flammarion una controversia propiamente tal, pues como ha descrito Gideon Freudenthal, esta consiste en un intercambio prometedor de argumentos sobre un desacuerdo científico que no puede ser resuelto por los medios disponibles ${ }^{46}$. Es decir, si hay posibilidad de resolver el desacuerdo mediante algún tipo de información disponible, ya sea observación, medición, experimentación o inferencia, la discusión no debería considerarse como controversia ${ }^{47}$. Por lo que en este sentido entre el científico francés y los astrónomos chilenos no hubo tal situación. Primero, porque la gran mayoría de los científicos pertenecientes a la comunidad internacional habían desmentido la posibilidad de que los gases tóxicos del Halley alcanzaran nuestra atmósfera con secuelas mortales, ya que la cola del cometa era menos densa que el más perfecto de los vacíos que podían producirse en un laboratorio, lo que había llevado a concluir que en el caso de que existiera una interacción entre la cola del Halley y la Tierra se produciría apenas una débil lluvia de meteoros ${ }^{48}$. Segundo, porque Camille Flammarion no contestó directamente a estos astrónomos locales a través de la prensa y tal vez ni se enteró de las críticas que se publicaron en Chile sobre sus textos, lo que determina que nunca hubo una controversia declarada entre ellos.

${ }^{43}$ Alan Gross, "Do disputes over priority tell us everything about science?", in Science in context, vol. 11, No. 2, Cambridge, 1998, pp. 161-179.

${ }^{44}$ Camille Flammarion, "Rencontre probable de la comète de Halley avec la Terre", dans Bulletin de la Société Astronomique de France et Revue Mensuelle d'Astronomie, de Météorologie et de Physique du Globe, vol. 24, Paris, 1910, pp. 27-31.

${ }^{45}$ Baeza, op. cit., p. 44; Ruiz-Castell, Suay-Mantallana y Bonet, op. cit., p. 174; Simoes, Zilhao, Diogo y Carneiro, op. cit., p. 207.

${ }^{46}$ Freudenthal, op. cit., p. 156.

${ }^{47}$ Ibid.

${ }^{48}$ William Wallace Campbell, "The return of Halley's comet”, in Publications of the Astronomical Society of the Pacific, vol. 21, No. 128, Chicago, 1909, pp. 188-195. Tiempo después el mismo Flammarion desmintió sus alusiones al peligro del Halley en Le Petit Journal: Ruiz-Castell, Suay-Mantallana y Bonet, op. cit., p. 174. 
No obstante, el desacuerdo de los científicos locales con el supuesto carácter mortal del cometa que difundió el astrónomo francés fue claro, y produjo que aquellos se pronunciaran sobre el portento para aclarar la situación. Por lo que, si bien no se desarrolló una controversia propiamente tal, de todos modos hubo una polémica -en palabras de Gideon Freudenthal- debido a que existió disentimiento entre unos y otros, y la discusión permeó hacia la sociedad ${ }^{49}$. Este último es un concepto más amplio y menos específico que el de controversia científica, pero su naturaleza también exige que el problema científico interactúe con el resto de la sociedad. El seguimiento de la polémica provocada por el Halley en Chile, en consecuencia, nos permite comprender la relación entre la discusión científica global y el escenario local.

El jueves 12 de mayo de 1910 -es decir, a pocos días del acercamiento máximo entre el cometa Halley y la Tierra- El Diario Ilustrado, dirigido hacia los estratos pudientes de la población santiaguina y cercano a los sectores conservadores, publicó una entrevista a Albert Obrecht, director del Observatorio Astronómico Nacional de Chile hasta el año 1908. En el texto el exdirector del OAN afirmó que no se debía temer en lo absoluto al cometa ni a su cola: "Puede estar usted seguro que ningún hecho de trascendencia se producirá si pasamos a través de ella. [...] Ningún periódico astronómico, ninguna revista seria trata de tal encuentro. [...] Hay algo de impresionismo para llamar la atención del público hacia un hecho común" 50 .

Los meses previos al paso del Halley fueron altamente propicios para que los astrónomos locales intentaran legitimarse frente a la sociedad y para que los medios captaran nuevos públicos a través de la alusión al fenómeno astronómico. El científico que se sirvió de esta oportunidad con mayor provecho en Chile fue Friedrich Ristenpart, quien fue el director del Observatorio Astronómico Nacional entre los años 1908 y 1913. Sus publicaciones y comunicaciones dirigidas a las audiencias locales fueron múltiples, y su trabajo de observación del Halley en el OAN comenzó el 5 de diciembre de 1909 y se extendió de forma casi ininterrumpida hasta el 12 de agosto de 1910, consiguiendo un total de ciento dieciocho vistas ${ }^{51}$. Durante ese periodo no solo observó el Halley, sino, también, otros cometas, conocimiento que fue publicado en los Anales de la Universidad de Chile $e^{52}$. En la misma revista científica, medio año después, Friedrich Ristenpart publicó una descripción de su participación en el IV Congreso Científico Panamericano

\footnotetext{
${ }^{49}$ Freudenthal, op. cit., p. 155.

50 "Sobre el Cometa Halley. Dos minutos con el Sr. Obrecht", en El Diario Ilustrado, Santiago, 12 de mayo de 1910, p. 3.

${ }^{51}$ Federico Ristenpart, "El Observatorio Astronómico Nacional en 1910”, en Anales de la Universidad de Chile, tomo 129, Santiago, 1911, p. 935.

52 En enero de 1910 Friedrich Ristenpart recibió un telegrama proveniente desde Johannesburgo (Sudáfrica) tras la aparición de un cometa que no había sido predicho por los astrónomos. Este astro fue observado por el director y los demás asistentes del OAN, llegando a la conclusión de que este cometa había pasado cerca del Sol perdiendo su brillo tras el perihelio: Federico Ristenpart, "Observaciones del gran cometa de enero de 1910 en Santiago de Chile", en Anales de la Universidad de Chile, tomo 126, Santiago, 1910, pp. 323-327. Otro cometa observado por Friedrich Ristenpart y su personal, publicado en esta revista, fue el Morehouse, el cual fue avistado en 1908 y el resultado de sus observaciones fueron publicadas en 1910. El cometa Morehouse fue el primer cometa analizado en el OAN cuando Friedrich Ristenpart asumió su dirección: Federico Ristenpart, "Observaciones del cometa 1908 C (Morehouse) con refractor de $24 \mathrm{~cm}$. del Observatorio Astronómico de Santiago”, en Anales de la Universidad de Chile, tomo 127, Santiago, 1910, pp. 811-827.
} 
en Buenos Aires en calidad de delegado del gobierno de Chile ${ }^{53}$, celebrado entre el $10 \mathrm{y}$ el 25 de julio de 1910, donde se refirió a su observación de la aproximación del Halley realizada en Santiago ${ }^{54}$. El director del OAN no solo difundió su trabajo en publicaciones científicas, ya que durante los meses previos al paso del cometa varios artículos y entrevistas suyas aparecieron en diarios y revistas dirigidos a todo tipo de público, actividad que complementó con conferencias divulgativas.

Los proyectos periodísticos que componen el corpus de este trabajo dan cuenta de una gran cobertura a sus conocimientos y quehaceres, y en todas estas instancias el astrónomo alemán presentó sus argumentos para no temer al paso del Halley, como puede evidenciarse en los siguientes casos. El 14 de abril de 1910 El Diario Ilustrado mencionó que el director "ha declarado que después de practicar diversas observaciones científicas, ha vuelto a encontrar al cometa Halley. En breve, empezará a dar la serie de conferencias que ha prometido sobre este asunto" ${ }^{55}$. En el texto puede leerse que Friedrich Ristenpart:

"Prepara una conferencia con proyecciones luminosas en el gran salón central de la Universidad, para dar cuenta de las apariciones que ofrecerá entonces el cometa [...]; y principalmente destruirá los muy visibles temores propagados por algunos astrónomos poco concienzudos e ignorantes del extranjero, reproducidos por una parte de la prensa, como si el paso del cometa por su línea de nodos el 18 de mayo pudiera tener alguna consecuencia desastrosa para la Tierra" ${ }^{96}$.

En lo recién referido es posible constatar que el director del Observatorio Astronómico Nacional intentó destacar el conocimiento local extraído de las observaciones de su equipo en Santiago, por sobre el saber dudoso y poco preciso producido en el extranjero, actitud que refleja la intención de legitimar el conocimiento científico sobre el cometa producido en Chile.

Más tarde, en su conferencia dictada en la Universidad de Chile el 25 de abril de $1910^{57}$, Friedrich Ristenpart aclaró quiénes eran esos extranjeros incultos, insistiendo en la calidad inofensiva de la cola del cometa:

"Todas las profecías de Flammarion hechas en febrero y marzo son solo vagas fantasías [...]. Los cálculos de mis observaciones [...] fueron anteayer comunicadas por nosotros por cable-

\footnotetext{
${ }^{53}$ Friedrich Ristenpart acudió al IV Congreso Científico en Buenos Aires con otros profesores de la Universidad de Chile, pero el astrónomo alemán fue uno de los pocos asistentes que tuvo la categoría de delegado del gobierno de Chile, lo que nos indica la confianza y relevancia que le dio la administración de Pedro Montt a la presencia del científico germano en este evento como uno de los representantes relevantes de la ciencia nacional: Decreto del ministro Emiliano Figueroa, Santiago, 1 de julio de 1910, en Archivo Nacional de la Administración (en adelante ARNAD), Fondo Ministerio de Educación, vol. 2730, f. 785.

${ }^{54}$ En este congreso científico, Friedrich Ristenpart pudo socializar con sus colegas provenientes de otros países americanos y aprovechó la instancia para presentar las fotografías obtenidas en el OAN del cometa Halley, que tenían una resolución menor en comparación con las obtenidas en el Observatorio de Córdoba: Federico Ristenpart, "Memoria del director del Observatorio Nacional sobre su actuación ante el IV Congreso Científico de Buenos Aires", en Anales de la Universidad de Chile, tomo 128, Santiago, 1911, pp. 281-294.

55 "El Cometa Halley encontrado nuevamente por nuestro Observatorio", en El Diario Ilustrado, Santiago, 14 de abril de 1910, p. 4.

${ }^{56}$ Ibid.

${ }^{57}$ Esta conferencia fue vendida en formato impreso en librerías.
} 
grama a los demás observatorios del mundo. Con esto puede ahora calcularse cuándo el cometa pasará por su nodo descendente. [...]. La Tierra, sin embargo, habrá pasado ya una hora y 25 minutos antes, por esta línea de nodos, y por consiguiente, no encontraría la cola del cometa"s8.

La identidad de los astrónomos negligentes esbozada por El Diario Ilustrado se delata en este fragmento, donde se patenta el propósito de rebatir a Camille Flammarion, utilizando para ello argumentos científicos sólidos sustentados en las observaciones que se habían realizado desde la institución chilena:

"Se ha hablado de combinaciones químicas que se podrían formar entre los elementos de la cola del cometa con la atmósfera, pero aquellos que de esto hablan olvidan que, dada la enorme velocidad del encuentro de ambos, todo lo que se introduzca de fuera a la atmósfera se quemaría allí arriba, muy lejos" ${ }^{59}$.

Tras su conferencia en la Universidad de Chile, El Diario Ilustrado volvió a difundir las actividades del astrónomo local. Así, el 3 de mayo de ese año se informó acerca de su nueva charla en el Club Alemán, a propósito "del acercamiento de la cola del cometa Halley a la Tierra, que ocurrirá el 18 de mayo" ${ }^{60}$. Luego, el 7 y 10 de ese mes, el periódico anunció la venta de la versión impresa de la conferencia dictada en la Universidad de Chile, donde, incluso, se detalló que los fondos obtenidos por este negocio serían donados para la construcción del futuro Hospital Alemán de Santiago, lo que vinculaba la actividad científica del astrónomo con una causa social valorada por la comunidad.

La figura del director del OAN también fue reconocida en otras regiones del país gracias al inminente paso del Halley. Así lo demuestra El Sur de Concepción ${ }^{61}$, en cuyas páginas se pueden leer varias noticias al respecto, tales como: que en su conferencia en la Universidad de Chile, Friedrich Ristenpart habría sido aplaudido con entusiasmo por la audiencia ${ }^{62}$, que su próxima presentación se realizaría el viernes 6 de mayo en el Círculo Naval dedicada a los oficiales de la Armada y al público general de la zona ${ }^{63}$, y que las puertas del OAN en Santiago estaban abiertas para que todo interesado pudiera observar el Halley con instrumentos profesionales ${ }^{64}$. En el mismo diario se remarcó en varias ediciones del mes de abril y mayo de ese año, que el director del Observatorio Astronómico Nacional estaba entre aquellos astrónomos que se oponían a la peligrosidad del paso del cometa, citando explicaciones suyas del fenómeno. Lo mismo ocurrió en El Mercurio de Valparaíso, en cuyas páginas aparecieron varias referencias a la divulgación del director del OAN y a su observación del Halley. En la edición del 28 de

\footnotetext{
${ }^{58}$ Federico Ristenpart, El cometa Halley: conferencia dada en el salón central de la Universidad de Chile, Santiago, Soc. Imp. y Lit. Universo, 1910, p. 49.

${ }^{59}$ Op. cit., p. 56.

60 "El Cometa de Halley. Conferencia del Señor Ristenpart", en El Diario Ilustrado, Santiago, 3 de mayo de 1910 , p. 2.

${ }^{61}$ En 1901, El Sur abrió una oficina de informaciones en Santiago, lo que le permitió estar en contacto con la contingencia noticiosa de la capital: Casanueva, op. cit., p. 264.

62 "El Cometa Halley", en El Sur, Concepción, 27 de abril de 1910, p. 2.

63 "Conferencia científica”, en El Sur, Concepción, 2 de mayo de 1910, p. 6.

64 "El Cometa Halley", en El Sur, Concepción, 26 de abril de 1910, p. 2.
} 
marzo, por ejemplo, se anunció que Ristenpart realizaría su famosa conferencia en la Universidad de Chile durante el mes de abril ${ }^{65}$; luego, el 14 de abril se aclaró que esta estaría basada en las observaciones que el mismo científico había realizado durante esos días ${ }^{66}$; finalmente, una vez dictada su presentación, apareció en la edición del 26 de abril una comunicación sobre las habilidades comunicativas del astrónomo y la gran concurrencia que tuvo el evento ${ }^{67}$.

La popularidad de Friedrich Ristenpart en esos meses sobrepasó, incluso, la temática del Halley, ya que también fueron cubiertas por la prensa otras iniciativas suyas no relacionadas con el cometa. Así, por ejemplo, el 12 de abril de ese año el diario El Industrial de Antofagasta señaló que el director del OAN había publicado la primera Carta del Hemisferio Celeste Austral, y que esta habría sido entregada "ayer tarde al Exmo. Señor Montt" ${ }^{\prime 68}$. De igual forma fue atendida su iniciativa para la construcción y traslado del Observatorio Astronómico Nacional desde la Quinta Normal hacia Lo Espejo, la que buscaba mejores condiciones para la contemplación del cielo. Este proyecto, así como otras actividades del científico, pudieron verse afectados de manera positiva gracias al papel mediático que alcanzó su figura en los meses previos al acercamiento del Halley ${ }^{69}$, oportunidad de la que estuvo consciente, como puede leerse en la versión impresa de su conferencia en la Universidad de Chile:

"Los astrónomos se dedican expresamente a buscar tales cometas con anteojos especiales, llamados en la fraseología astronómica 'Busca-cometas', instrumentos de fácil manejo y de gran potencia luminosa y que a la vez permiten abarcar considerables extensiones del cielo. Cuando nuestro Observatorio Astronómico se encuentre instalado en su nuevo terreno, dedicará también su excelente busca-cometas a la caza de estos eternos errantes. Y lo hará seguramente con éxito, por el hecho de existir pocos observatorios en el hemisferio austral y muy pocos dedicados a esta tarea de la caza"70.

Con este y otros comentarios del astrónomo se demuestra que aprovechó la expectación originada por el cometa Halley para defender la relevancia del desarrollo del saber astronómico por sobre otros, justificando, de este modo, la construcción de las nuevas instalaciones del OAN, así como la compra de nuevos instrumentos científicos.

Las revistas, especialmente los magazines ilustrados de amplio tiraje y circulación, también cubrieron el fenómeno. Sin centrarse tanto en las noticias específicas asociadas al Halley, sino, más bien, abordándolo desde una perspectiva que se debatía entre el sensacionalismo y la llamada a la calma de la población, algunas de estas publicaciones,

65 “El Cometa Halley”, en El Mercurio, Valparaíso, 28 de marzo de 1910, p. 7.

66 "El Cometa Halley encontrado nuevamente por nuestro Observatorio. Datos interesantes", en El Mercurio, Valparaíso, 14 de abril de 1910, p. 7.

67 "El Cometa Halley", en El Mercurio, Valparaíso, 26 de abril de 1910, p. 1.

68 "Carta astronómica", en El Industrial, Antofagasta, 12 de abril de 1910, p. 1.

${ }^{69}$ Esta oportunidad brindada por el Halley se vinculó a otras situaciones locales que también favorecieron al director del OAN, como el caso del terremoto de 1906 con epicentro en Valparaíso y sus posteriores réplicas, en una época en que los sismógrafos todavía se encontraban dentro de los observatorios astronómicos. Friedrich Ristenpart llegó a Chile en 1908, mismo año en que recién se fundaría el Servicio Sismológico Nacional, por lo que aún se asociaba al director del OAN como la autoridad en materia sísmica: Valderrama, "La catástrofe anunciada...”, op. cit., pp. 169-195; Valderrama, Observando la catástrofe..., op. cit., pp. 274-276.

${ }^{70}$ Ristenpart, El cometa Halley..., op. cit., p. 16. 
tales como Corre-Vuela y Sucesos, hicieron referencias al cometa desde 1909, concentrando su mayor dedicación al fenómeno entre marzo y mayo de 1910. En las revistas revisadas -en especial en Sucesos- también se puede percibir una amplia cobertura a las actividades y proyectos de Friedrich Ristenpart durante ese año, sobre todo al traslado de las instalaciones del Observatorio ${ }^{71}$. En 1909, por ejemplo, este magazine publicó un foto-reportaje donde se entregaban detalles sobre el nuevo observatorio. En él pueden verse imágenes del equipamiento científico, las instalaciones y el personal astronómico, y su texto elogia la administración de Ristenpart, argumentando que estas nuevas instalaciones pondrían a Chile en un circuito astronómico de primer nivel:

"Desde que el Dr. Federico Ristenpart tomó la dirección del Observatorio Astronómico Nacional, los servicios de esta oficina han entrado a un camino de visible progreso; y si el gobierno continúa prestando atención e interés a las indicaciones del Dr. Ristenpart, podrá en breve tiempo el país enorgullecerse de poseer un observatorio astronómico que se halle a la altura de los adelantos modernos de esta ciencia" ${ }^{\prime 2}$.

\section{Figura 1 \\ “Observatorio Astronómico de Santiago”, 1930}
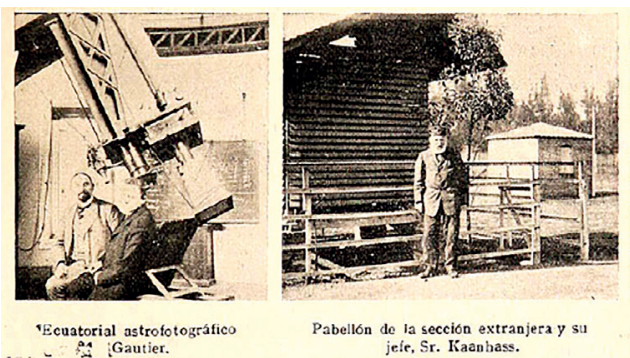

Pabellón de la sección extranjera y su
jele, Sr. Kaanbass.

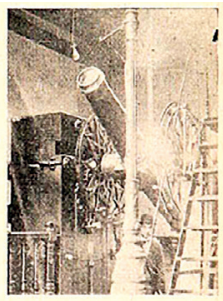

Circulo meridiano.
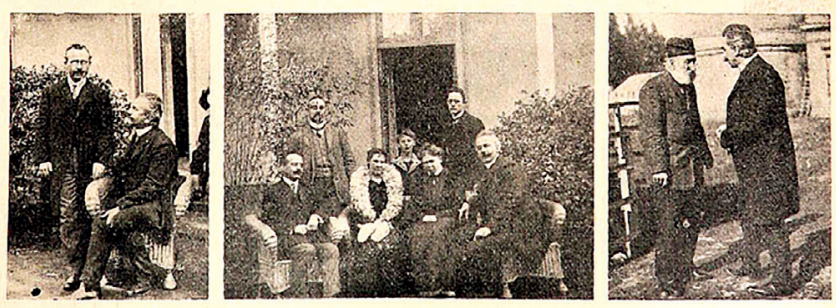

Mr. Curtis $\vee$ Dr. Ristenpart, Idirectores de los observaítorios de la Quiata N ormal Grupo general de los astróaomos de Santiago,
Mr. Curtis, Sra. Curtis. Sra, Ristenpart, Dr.
Ristenpart, Dr. Zurbelien, Dr. Prager, nižo
Ristenpart.

EI Dr. Ristenpart y el
Sr. Kaahaass. pectivamente.

Fuente: Sucesos, n. ${ }^{\circ}$ 354, Valparaíso, 17 de junio de 1909, s/p.

${ }^{71}$ El traslado del Observatorio a Lo Espejo se comenzó a gestionar en septiembre de 1909. Para los meses de observación del Halley, el nuevo establecimiento ya contaba con el Pabellón Ecuatorial Astro-Fotográfico, la casa del jefe del Ecuatorial y la casa del primer astrónomo, quedando en ejecución el Pabellón Principal, las porterías y la planta eléctrica: Observatorio Lo Espejo, copia presupuesto i estado trabajos, Santiago, 24 de enero de 1911, en ARNAD, Fondo Ministerio de Obras Públicas, vol. 2187, f. 324.

72 “Observatorio Astronómico de Santiago", en Sucesos, n. ${ }^{\circ}$ 354, Valparaíso, 17 de junio de 1909, s/p. 
En otros magazines, como Zig-Zag, se abrió un espacio para que una segunda institución astronómica, recién instalada en Santiago, también pudiera darse a conocer entre la población. Este fue el caso del Observatorio Lick del Sur, ubicado en el cerro San Cristóbal desde 1903, y que fue fruto de la expedición estadounidense proveniente de la Universidad de California, que viajó a Chile para elaborar un catálogo de velocidades radiales de estrellas brillantes del hemisferio $\mathrm{Sur}^{73}$. Zig-Zag ofreció la oportunidad al director de dicho Observatorio, Joseph H. Moore (1878-1949), para que también se diera a conocer dentro de la comunidad local. La revista señalaba: "Moore ha tenido la galante deferencia de resumir en una luminosa disertación escrita, que tenemos a la vista, los resultados obtenidos en sus observaciones científicas del cometa Halley"74. Junto con ello, añadió las ventajas técnicas de este nuevo centro, afirmando que sus registros "son las primeras y únicas fotografías que se tomaron de este cometa en nuestro país durante su visita"75. Esta aseveración final demuestra una declarada intención de favorecer a la nueva autoridad astronómica en el país, puesto que se permite negar (o ignorar) sin disimulo, que el OAN también había hecho registros fotográficos del Halley durante todos esos meses.

Se debe tener en cuenta que Friedrich Ristenpart venía haciendo grandes esfuerzos por cambiar la mala imagen del OAN, debido a que en los últimos años bajo la administración de Albert Obrecht esta institución tuvo problemas de presupuesto que mermaron de manera considerable los trabajos científicos. En particular, no pudo cumplir con sus obligaciones en el proyecto global de la Carte du Ciel para el catálogo de las estrellas de los cielos australes, lo que repercutió negativamente en el prestigio internacional del Observatorio $^{76}$. Friedrich Ristenpart estuvo consciente de esta situación y en su obra Astrónomos alemanes en Chile (1910) aprovechó la situación para esgrimir algunas críticas a su colega francés: "Sólo mencionaremos, que en los 21 años de su directorio [-Albert Obrecht-] no se ha observado el reglamento del Observatorio, como tampoco se hizo en los 22 años anteriores" ${ }^{\text {77 }}$. Frente al descrédito en el que había caído el establecimiento, el paso del cometa Halley favoreció al nuevo director para poner nuevamente al OAN en la palestra pública y así justificar las reformas que estaba realizando. Por lo cual sus apariciones en la prensa diaria y periódica, al desmentir las posibles consecuencias que traería consigo la cercanía de este cuerpo celeste con la Tierra, se convirtieron en una estrategia para validar su experiencia ante la población lectora del país y las autoridades políticas, así como para cambiar la imagen del Observatorio.

\footnotetext{
${ }^{73}$ Bárbara Silva, Estrellas desde el San Cristóbal. La singular historia de un observatorio pionero en Chile, Santiago, Catalonia, 2019, pp. 36-37. El Observatorio Lick del San Cristóbal para 1910 estaba negociando mayores recursos económicos con su filial estadounidense para poder mantenerse en el hemisferio Sur. En cuanto a los trabajos científicos, estos estuvieron abocados al registro de los espectros de estrellas binarias, también se observaron algunos cometas y el director de la institución tuvo la intención de participar en el Congreso Científico Panamericano celebrado en Buenos Aires, pero estuvo limitado por problemas económicos: Op. cit., pp. 122-123.

74 “El Cometa Halley", en Zig-Zag, n. . 277, Santiago, 11 de junio de 1910, s/p.

${ }^{75}$ Ibid.

${ }^{76}$ Keenan, Pinto y Álvarez, op. cit., pp 125-126.

${ }^{77}$ Federico Ristenpart, Astrónomos alemanes en Chile, Santiago, Imprenta Universitaria, 1910, p. 12.
} 
La aparición de Friedrich Ristenpart en los medios escritos e informativos ya se había producido antes del advenimiento del Halley ${ }^{78}$, aunque con menor intensidad. En 1909 y a principios de 1910 publicó dos obras que estaban pensadas para un público general y que no versaban sobre el cometa: Almanaque astronómico para el año 1910 (1909) y la recién nombrada Astrónomos alemanes en Chile (1910). Estas obras estuvieron disponibles en librerías y en la Biblioteca Nacional, donde los lectores tuvieron acceso a ellas de forma gratuita ${ }^{79}$. El mismo astrónomo se encargó de que estas publicaciones estuvieran disponibles dentro y fuera del país, como le manifestó al director de la Biblioteca en una carta el 14 de marzo de 1910: "[...] me permito manifestarle que este Observatorio Astronómico ha hecho ya una gran remesa de sus publicaciones tanto dentro del país como al extranjero, por lo tanto, ruego a Ud. comunicarme las 70 direcciones a las cuales mandan el canje para evitar que se remitan dos ejemplares al mismo destinatario" "80. A la publicación de estos libros, se sumaron sus artículos científicos incluidos en los Anales de la Universidad de Chile, algunas conferencias y sus clases de astronomía dictadas en esta misma casa de estudio desde $1909^{81}$.

También se debe mencionar la actividad de divulgación que proyectaba Ristenpart en las futuras dependencias del Observatorio, en Lo Espejo, sobre lo cual él mismo declaró:

"El nuevo Observatorio de Lo Espejo tendrá en su edificio central, un gran salón de conferencias con un aparato de proyección de Zeiss de primer orden, y es mi intención que entonces cada domingo en la tarde se dé allí, por uno de los empleados del Observatorio, conferencias con proyecciones luminosas sobre cualquier tema relacionado con la astronomía" ${ }^{\prime 22}$.

Todas estas referencias dan cuenta de que el nuevo director del OAN inició su cercanía con la prensa local desde su arribo a Chile en 1908. Sin embargo, el advenimiento del cometa Halley en 1910 aumentó significativamente su presencia en los medios, lo que significó que pudiese disponer de mayor atención no solo para informar a las audiencias, sino, también, para intentar validarse como autoridad astronómica y para justificar la relevancia de disponer recursos para el desarrollo de esta ciencia.

\section{UN COMETA PELIGROSO VISTO DESDE EL SUR DEL MUNDO}

Los diarios y revistas publicaron colaboraciones sobre las observaciones del Halley provenientes de distintos puntos del planeta, tales como: Italia, Brasil, Argentina, España, México, entre otros, tomando, a menudo, sus referencias desde periódicos extranjeros. Esta dinámica propició confusiones y una circulación de conocimientos no necesaria-

\footnotetext{
${ }^{78}$ Verónica Ramírez, "Expertos y profanos: circulación del saber astronómico en magazines chilenos (19001920), en Revista de Humanidades, n. ${ }^{\circ}$ 40, Santiago, 2019, pp. 235-272.

${ }^{79}$ Boletín de la Biblioteca Nacional, n. ${ }^{\circ} 75$, Santiago, 1910, p. 54.

${ }^{80}$ Carta de Federico Ristenpart al Señor Director de la Biblioteca Nacional, Santiago, 14 de marzo de 1910, en Archivo Nacional Histórico, Fondo Biblioteca Nacional, vol. 70, f. 142.

${ }^{81}$ Federico Ristenpart, Clases de astronomía profesadas en la Universidad de Santiago de Chile, Santiago, Imprenta Cervantes, 1912.

${ }^{82}$ Ristenpart, El cometa Halley..., op. cit., p. 62.
} 
mente avalados por los científicos, por lo que los astrónomos locales se sintieron llamados a encausar la lectura de las audiencias, lo que, a su vez, generó un espacio para que aquellos se dieran a conocer frente a dichos públicos, como se ha intentado demostrar. La legitimación de estas figuras, no obstante, dependió directamente de la disputa científica; es decir, de la persistencia de una contraparte que defendiera y propagara la peligrosidad del acercamiento del Halley. En consecuencia, para comprender la relevancia que adquirió Friedrich Ristenpart, en este caso, es necesario revisar cómo circuló el discurso contrario, cuya responsabilidad en el contexto chileno, al igual como ocurrió en otras regiones, se adjudicó a la figura del astrónomo francés Camille Flammarion.

La peligrosidad del acercamiento del cometa en 1910 se transmitió a partir de la observación científica de la toxicidad de los componentes del astro (gas cianógeno) y de la posible interacción de su cola con la atmósfera terrestre. Este pensamiento, como explica Owen Gingerich, fue alimentado gracias a los adelantos tecnológicos de la astrofísica, que posibilitaron la creación del análisis espectroscópico que podía identificar los elementos constitutivos de los cuerpos celestes ${ }^{83}$. A este contexto científico debe añadirse que en 1908 el astrónomo Walter Morehouse (1876-1941) descubrió un nuevo cometa $^{84}$, que según el análisis espectroscópico de su contorno portaba gases altamente tóxicos para los seres humanos ${ }^{85}$. El cometa analizado por este científico no despertó mayor preocupación, porque se encontraba lejos de la Tierra y no podía percibirse a simple vista, pero encendió la alarma respecto del inminente paso del Halley, del cual sí se proyectaba un acercamiento significativo con nuestro planeta. A pesar de que la mayoría de los astrónomos descartaron los riesgos de la interacción de este astro con la atmósfera, "los divulgadores científicos habrían de explotar la incertidumbre de un posible paso de la Tierra por la cola del cometa" $"$.

Uno de los más destacados en ese sentido, sobre todo por la inmensa distancia que recorrieron sus textos, fue el astrónomo francés Camille Flammarion ${ }^{87}$, a quien ya nos hemos referido. Para entonces, este ya era reconocido en el ámbito mundial por su papel como difusor y popularizador de la astronomía. Su estrategia para difundir la ciencia consistió en amalgamar la escritura científica con la literaria, desplazándose desde el dato científico a la ficción y viceversa, publicando una enorme cantidad de textos divulgativos con estas características, así como novelas de ciencia-ficción ${ }^{88}$.

\footnotetext{
${ }^{83}$ Owen Gingerich, Astrophysics and Twentieth-Century Astronomy to 1950, London, Cambridge University Press, 1984.

${ }^{84}$ Este cometa fue observado por Ristenpart y su personal en el OAN, pero dadas las malas condiciones en que se encontraban los instrumentos ópticos, las imágenes obtenidas eran poco satisfactorias: Ristenpart, "Observaciones del cometa 1908...", op. cit., p. 811.

${ }^{85}$ Ruiz-Castell, Suay-Mantallana y Bonet, op. cit., p. 174.

${ }^{86}$ Ibid.

${ }^{87}$ Flammarion a inicios del siglo XX era reconocido como el astrónomo más afamado a escala mundial, tanto por sus contemporáneos como por él mismo, gracias a que sus obras se tradujeron a distintos idiomas y sus libros fueron leídos en diversos países, convirtiéndolo en una figura popular en el ámbito científico: Camille Flammarion, Memorias biográficas y filosóficas de un astrónomo, París, Librería de la Vda. de Ch. Bournet, 1913, p. 4.

${ }^{88}$ Verónica Ramírez, "Predicciones del fin del mundo: Astronomía y ciencia ficción en los magazines de editorial Zig-Zag (1900-1920)”, en Literatura y Lingüística, n. ${ }^{\circ}$ 40, Santiago, 2019, pp. 69-81.
} 
Las ideas apocalípticas de este francés habían comenzado a difundirse en la prensa chilena años antes del paso del Halley. Zig-Zag, por ejemplo, publicó en mayo de 1905 un artículo de divulgación de su autoría titulado, al igual que su novela, "El fin del mundo". En sus páginas, Camille Flammarion explicaba, a partir de datos científicos, los graves daños que podría ocasionar a la Tierra el choque con otros astros y en especial con cometas. El acontecimiento astronómico que inspiró este texto del divulgador fue la observación del estallido de una estrella de la constelación de Perseo el 23 de febrero de 1901, tras lo cual el cuerpo celeste habría desaparecido. La explicación científica de la posible causa de este hecho, proporcionada por el autor, alimentó la imaginación y el sensacionalismo, sobre todo al enfatizar que "un encuentro con otro cuerpo celeste no es por lo tanto imposible y según todas las probabilidades se ve por el examen de la misma irradiación de la estrella de Perseo que la conflagración se ha producido a causa de un encuentro, por un choque violento" 89 . Luego, tras señalar que sería poco probable que dos planetas llegaran a interactuar, el autor expuso en su texto que existía mayor posibilidad de que un cometa y un planeta sí lo hiciesen con resultados fatales, describiendo, a continuación, cuáles podrían ser los efectos de dicho encuentro: "El incendio se declararía muy luego; nuestra atmósfera se inflamaría como una ponchera. No se producirían cientos, sino miles de grados. El oxígeno del aire le costaría muy poco para alimentar las llamas, y el hidrógeno del mar se desprendería muy fácilmente" ${ }^{90}$.

Una de las ideas tratadas por este texto, que volvió a recordarse cuatro años después en el contexto del Halley, fue la hipótesis de que una mezcla cometaria de óxido de carbono con nuestra atmósfera traería la supresión rápida de todas las respiraciones por medio del envenenamiento de la sangre ${ }^{91}$, situación que también fue ilustrada con dibujos que mostraban a las personas asfixiadas realizando una serie de actos disparatados producto de la falta de oxígeno en el aire (fig. 2).

Las refutaciones hacia publicaciones como estas no tardaron en aparecer en las páginas de este y otros magazines, actitud que se vinculó con otros fenómenos predictivos tratados con igual sensacionalismo en la prensa. En Chile, en particular, entre los años 1906 y 1912 se dio una importancia semejante al augurio de sismos, puesto que las audiencias habían incorporado en su imaginario la posibilidad de predecirlos. El terremoto en Valparaíso del 16 de agosto de 1906 fue "augurado" un día antes por El Mercurio de Valparaíso, gracias a una nota publicada en este periódico firmada por el capitán Arturo Middleton, jefe de Meteorología de la Dirección del Territorio Marítimo ${ }^{92}$. La nota, que había pasado desapercibida el día 15, cobró gran relevancia al producirse el terremoto, y por más que otros científicos explicaron a la población que la predicción de sismos no era posible debido a que aún no se conocían las causas de este fenómeno, la idea de que la ciencia sí podía augurar y prevenir este y otro tipo de catástrofes, quedó instalada ${ }^{93}$. Los sismos y los cometas no solo se vieron enlazados por su vinculación a las profecías, sino, también, porque para entonces era muy popular la teoría de Alfred Cooper -en la

\footnotetext{
${ }^{89}$ Camille Flammarion, "El fin del mundo", en Zig-Zag, n. ${ }^{\circ}$ 12, Santiago, 7 de mayo de 1905, p. 4.

${ }^{90}$ Ibid.

${ }^{91}$ Op. cit., p. 6.

92 "Pronóstico sobre fenómenos atmosféricos", en El Mercurio, Valparaíso, 15 de agosto de 1906, p. 5.

${ }^{93}$ Valderrama y Ramírez, op. cit.
} 
que se había basado Middleton para escribir su nota- que vinculaba los movimientos terrestres a la influencia de los astros ${ }^{94}$.

\section{FiguRA 2}

Camille Flammarion, "El fin del mundo" (1905)

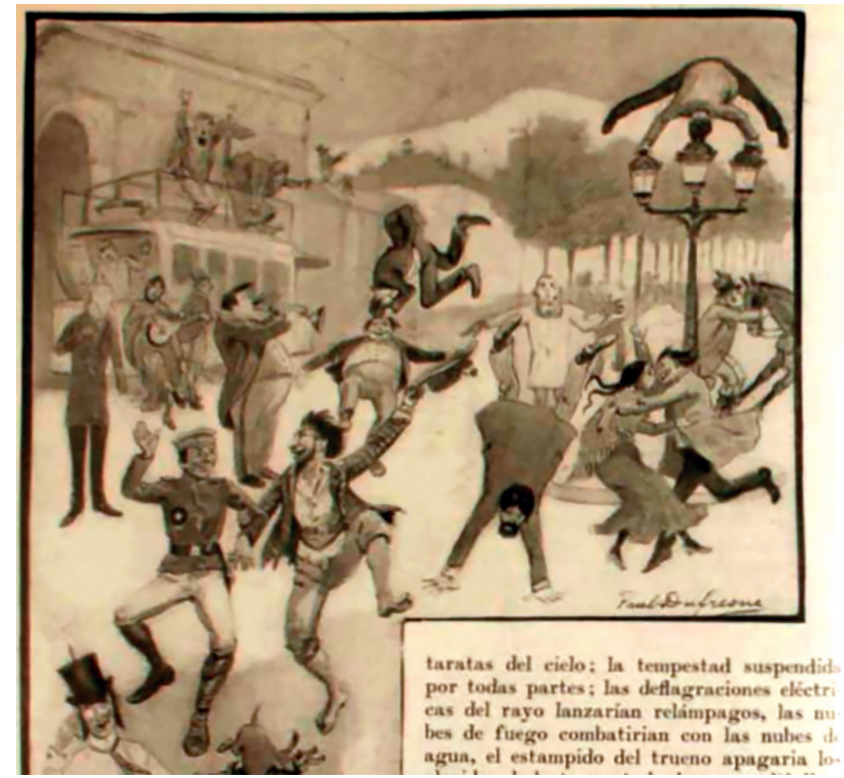

Fuente: Zig-Zag, n. ${ }^{\circ}$ 12, Santiago, 7 de mayo de 1905, p. 6.

A esto último se debe sumar, además, que las fronteras entre la astronomía, la sismología y la meteorología eran difusas en la época, y que a falta de una institución estatal dedicada de forma exclusiva a la sismología (esta recién se creó en 1908), los sismógrafos se encontraban dentro de los observatorios astronómicos. Esta situación contribuyó a que las audiencias - conformada por periodistas, autoridades civiles, ciudadanos, etc.exigieran a los astrónomos la aclaración de conocimientos asociados a los terremotos. A partir de lo anterior se podría inferir que cuando los medios se pronunciaron sobre el cometa en 1910, también pensaron en la amenaza de posibles sismos y en el desastre que había dejado el terremoto de 1906. Las teorías de Alfred Cooper y Camille Flammarion fueron asociadas por estas audiencias y combatidas por Friedrich Ristenpart, como puede constatarse en una entrevista de revista Zig-Zag, donde afirmó que la teoría de Cooper era absurda ${ }^{95}$.

${ }^{94}$ Valderrama, "La catástrofe anunciada...", op. cit., p. 171; Valderrama, Observando la catástrofe..., op. cit., p. 241.

95 "La teoría de Cooper. Con el director del Observatorio Astronómico Nacional", en Zig-Zag, n. ${ }^{\circ}$ 394, Santiago, 7 de septiembre de 1912, s/p. 
El 2 de febrero de 1910 el magazine Corre-Vuela despertó inquietud con el título "El cometa que se acerca puede chocar con la Tierra", refiriéndose a Camille Flammarion para respaldar dicho argumento: "El hecho es muy posible en opinión del eminente astrónomo Camilo Flammarion" ${ }^{96}$. Tras este texto la temática del fin del mundo quedó instalada en la revista durante los meses previos al Halley. Algo parecido ocurrió en la revista Sucesos, donde el 17 de marzo de ese año se incluyó un texto divulgativo cuyas ilustraciones también pertenecían a Camille Flammarion, y en el que se afirmaba que "el análisis espectral ha comenzado y no es fácil predecir si el cianógeno que se acaba de descubrir en el núcleo se esparcirá por la cola del cometa"97. El 30 de marzo, Corre-Vuela volvió a pronunciarse sobre la problemática a través del texto "Después de la muerte de la Tierra", en cuyas líneas se expusieron nuevas palabras del astrónomo francés que enfatizaban en el motivo de la destrucción del planeta: "Dentro de diez millones de años, dice Camilo Flammarion, si nuestro planeta no ha muerto de accidente, morirá de vejez"98. La misma revista incluyó el 13 de abril el texto "La Tierra sin atmósfera", en el que se describían las consecuencias que podría traer el deterioro del aire que rodea al planeta, haciendo evidente alusión a la interacción con la peligrosa cola del Halley. Este texto se iniciaba con una inquietante introducción: "Además de la imposibilidad de respirar, observaríamos muchas cosas raras si la Tierra se quedase sin atmósfera" ${ }^{99}$. El 23 de abril, por otra parte, Zig-Zag publicó un poema del escritor Antuco Antúnez acompañado de una ilustración que hacía referencia directa al fin del mundo (fig. 3), y cuyos versos mencionaban lo siguiente:

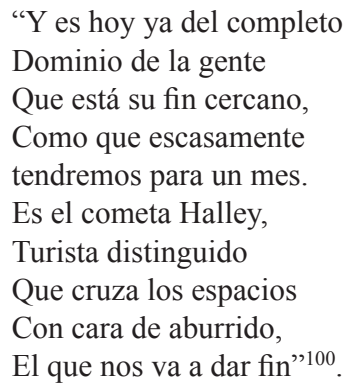

Todas estas fuentes revelan que las audiencias estaban totalmente familiarizadas con la idea destructiva del Halley, situación que también es posible de constatar en la prensa diaria. En El Diario Ilustrado del 22 de abril se explicitó este motivo a través de las respuestas del astrónomo Gustave Leveau, del Observatorio de París: “iQué choque! Aquel sería por cierto el fin del mundo. Algo se modificarían las condiciones de nuestro planeta, pero os repito nos basamos en verdaderas hipótesis" ${ }^{\prime 101}$. El 15 de mayo, el mismo diario publicó

96 "El cometa que se acerca puede chocar con la Tierra", en Corre-Vuela, Santiago, 2 de febrero de 1910, s/p.

97 "Cosas del cielo", en Sucesos, Valparaíso, 17 de marzo de 1910, s/p.

98 "Después de la muerte de la Tierra", en Corre-Vuela, Santiago, 30 de marzo de 1910, s/p.

99 "La Tierra sin atmósfera", en Corre-Vuela, Santiago, 13 de abril de 1910, s/p.

${ }^{100}$ Antuco Antúnez. “¡Ya viene!”, en Zig-Zag, n. o 370, Santiago, 23 de abril de 1910, s/p.

101 "A propósito del Cometa. Traducido por el Diario El Ilustrado", en El Diario Ilustrado, Santiago, 22 de abril de 1910, p. 1. 
una noticia de Italia, que refería que: “Los campesinos están espantados, esperando sobrevengan grandes calamidades"102, así como un cuento nacional de Misael Guerra titulado "Esperando el cometa", en el que se hacía alusión a los temores despertados por el cometa de 1907 y cómo se relacionaba este con el Halley ${ }^{103}$. A su vez, el 2 de mayo, el diario $E l$ Sur señaló que Camille Flammarion estaba dentro de los sabios que daba como posible que se siguieran consecuencias graves para la Tierra debido al choque del Halley ${ }^{104}$.

Figura 3

Antuco Antúnez, "¡Ya viene!”

(1910)
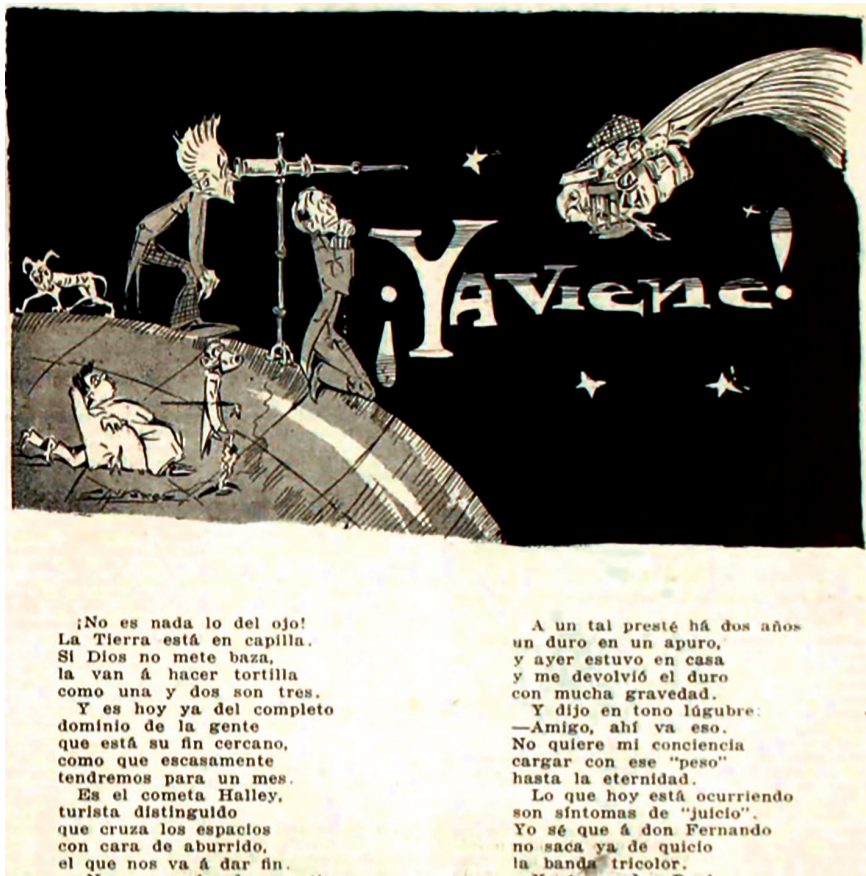

A un tal presté há dos años

un duro en un apuro.

y ayer estuvo en casa
y me devolvio el duro

y me devolvio el duro

$\mathrm{Y}$ aljo en tono lagubr

No quigre mi va eso.

cargar con ese "peso"

hasta la eternidad.

Lo que hoy esta ocurriendo

on sintomas de "juiclo".

Yo sé que a don Fernand.

no saca ya de quicto

$\mathbf{Y}$ se que don Dario

iNo es prueba de que tiene

Fuente: Zig-Zag, n. ${ }^{\circ}$ 370, Santiago, 23 de abril de 1910, s/p.

De igual forma, el 12 de mayo en El Mercurio de Valparaíso se incluyó la noticia de que en España "a medio día de hoy se vio un súbito resplandor intenso rojizo que alarmó a la muchedumbre. En seguida se nubló bruscamente oscureciéndose las calles, atribuyéndose estas variaciones a la cercanía del cometa"105. Después, en el diario El Industrial de Antofagasta aparecieron múltiples referencias alarmistas sobre el fenóme-

\footnotetext{
102 "Italia. El cometa", en El Diario Ilustrado, Santiago, 15 de mayo de 1910, p. 10.

${ }^{103}$ Misael Guerra, "Esperando el cometa”, en El Diario Ilustrado, Santiago, 15 de mayo de 1910, p. 10.

104 "El Cometa Halley", en El Sur, Concepción, 2 de mayo de 1910, p. 7.

105 “España. Variaciones atmosféricas”, en El Mercurio, Valparaíso, 12 de mayo de 1910, p. 5.
} 
no astronómico. El 25 de abril se señaló en sus páginas que en Santiago los habitantes ya habían comenzado a observar el Halley con curiosidad y pavor ${ }^{106}$. Luego, el 13 de mayo, un artículo titulado "El terrible cometa" explicó que "cuando su tránsito se anunció, hubo un movimiento de expectación en el mundo... Los señores astrónomos, siguiendo a Flammarion, el poético soñador del Infinito, se dieron a profetizar horrores" ${ }^{\prime 107}$. Por último, el día 16 de mayo un nuevo texto en el periódico adjudicó ciertos cambios atmosféricos a la cercanía del Halley ${ }^{108}$.

Todas estas alusiones al fenómeno permiten corroborar que existieron audiencias interesadas en el cometa, así como que se habían forjado circunstancias propicias, no solo para la búsqueda de legitimación de los astrónomos y de la astronomía local, sino, también, para generar un mercado editorial a propósito del Halley, como se expone en el siguiente apartado.

\section{LA CONSOLIDACIÓN DE UN MERCADO EDITORIAL EN TORNO AL HALLEY}

Como se visualiza en los apartados anteriores, el paso del cometa Halley en 1910 promovió la circulación del conocimiento astronómico más allá de las páginas de las publicaciones académicas. El Halley rebasó esos límites y el saber sobre este astro se propagó en medios de múltiples características, que interpelaron a audiencias heterogéneas, como la prensa diaria y los magazines. Asociado al tránsito de este cuerpo celeste se estableció un mercado que promovía variados productos a través de avisos publicitarios en la prensa; esto en un contexto en que gran parte de los periódicos se habían convertido en empresas comerciales. Como ha sido estudiado para el caso de Portugal, los diarios utilizaron al Halley para promover la venta de vinos, combustibles y fármacos, empleando a la ciencia en sí como una certificación de la calidad de los productos ofre$\operatorname{cidos}^{109}$. Asimismo, el carácter sensacionalista de las predicciones de astrónomos como Camille Flammarion fue capitalizado por los periódicos portugueses y españoles para vender más ejemplares, optando por un tono más escandaloso para, de ese modo, vencer la competencia entre las empresas editoriales ${ }^{110}$.

En Chile, previo al paso del Halley, ya se había establecido un mercado publicitario de productos asociados a otras ciencias, como la medicina, tal como ha demostrado María José Correa para el caso de los productos farmacéuticos y terapéuticos, entre otros ${ }^{111}$.

\footnotetext{
106 "El Cometa Halley", en El Industrial, Antofagasta, 25 de abril de 1910, p. 1.

107 "El terrible cometa", en El Industrial, Antofagasta, 13 de mayo de 1910, p. 1.

108 "Iquique. Lluvia, relámpagos y truenos. Pánico en la población. El temor al Cometa", en El Industrial, Antofagasta, 16 de mayo de 1910, p. 1.

${ }^{109}$ Simoes, Zilhao, Diogo y Carneiro, op. cit., p. 206.

${ }^{110}$ Op. cit., p. 209; Ruiz-Castell, op. cit., pp. 177-178.

${ }^{111}$ María José Correa, "Casas comerciales y boticas. Aproximaciones al desarrollo del mercado médico en el Chile urbano, 1860-1910”, en Revista de Historia Social y de las Mentalidades, vol. 18, n. ${ }^{\circ}$ 1, Santiago, 2014, pp. 9-33; María José Correa, “'Brulote disfrazado, no oblea medicinal'. El avance de los específicos en el Chile urbano del Centenario", en Yuri Carvajal y María José Correa (eds.), Historia de los medicamentos. Apropiaciones e invenciones en Chile, Argentina y Perú, Santiago, Ocho Libros Editores, 2016, pp. 85-108.
} 
Por lo que el tránsito del Halley fue utilizado del mismo modo por la prensa nacional para promocionar diversos productos, activando, de esta forma, un mercado en torno al evento astronómico, lo cual se pudo ver reforzado y acentuado por la celebración del centenario de la República que provocó un aumento de los avisos publicitarios en la prensa debido a la fuerte competencia y apuesta comercial que las tiendas tuvieron al ofrecer a su clientela diversos productos de consumo masivo dirigidos a estratos sociales diferenciados, aprovechando la efervescencia de las festividades republicanas ${ }^{112}$.

El cometa, asimismo, incentivó en Chile la circulación de otro tipo de medios, como los folletos o libros pequeños con la transcripción de las conferencias divulgativas sobre el Halley que dictó Friedrich Ristenpart en la Universidad de Chile, en el Club de Marina en Valparaíso y frente a la comunidad alemana; ediciones que se publicitaron en la misma prensa, como fue el caso de El Diario Ilustrado, el 7 de mayo de 1910, donde se lee: "En folleto, correctamente impreso, el director del Observatorio Astronómico, profesor Federico W. Ristenpart, ha publicado la conferencia que dio últimamente en el Salón de la Universidad del Estado acerca del cometa Halley. Desde hoy se encontrará a la venta en todas las librerías a un peso" ${ }^{113}$. El Mercurio de Valparaíso también hizo eco de esta información: "El distinguido profesor señor Ristenpart, cuya conferencia acerca del cometa Halley, ha sido justamente celebrada por el público de nuestro puerto, ha tenido la feliz idea de hacer imprimir en folleto su trabajo, publicando dos ediciones iguales, una en español y otra en alemán"114. Este tipo de avisos permite constatar que hubo una alta demanda de parte de distintos públicos que deseaban saber más sobre este fenómeno astronómico, situación que favoreció la venta de diversos productos impresos, así como el establecimiento de un negocio basado en el Halley.

El portento celeste se puso de moda de tal manera que el comercio de los más variados productos se vinculó con el fenómeno astronómico, lo que conllevó a que la publicidad gráfica se volcara hacia este motivo durante los meses previos al acercamiento del cometa, como puede verse en los siguientes ejemplos iconográficos que se describirán a continuación.

El interés de las casas comerciales en el Halley se vio reflejado en la publicidad gráfica contenida en los magazines, donde se promocionaron productos como té y aceite; y se aprecia el nombre de estos bienes de consumo simulando la forma del cometa o a observadores que estaban contemplando el fenómeno cósmico, aprovechando visualmente la instancia que les ofrecía este evento astronómico. Avisos gráficos con una fuerte apuesta visual y publicitaria como el de Té Dulcinea o el del Té Horniman eran bastante comunes en los periódicos y los magazines, los cuales tenían sucursales y puestos de ventas en ciudades como Valparaíso y Santiago (figs. 4 y 7) ${ }^{115}$. Por otra parte, algunos locales comerciales utilizaron las predicciones sensacionalistas que se generaron en tor-

\footnotetext{
${ }^{112}$ Pedro Álvarez (ed.), Historia gráfica de la propiedad intelectual en Chile, Santiago, Instituto Nacional de Propiedad Intelectual, 2010, p. 57.

113 “El Cometa Halley”, en El Diario Ilustrado, Santiago, 7 de mayo de 1910, p. 6.

114 "La conferencia sobre el cometa. Idea filantrópica", en El Mercurio de Valparaíso, Valparaíso, 8 de mayo de 1910, p. 9.

${ }_{115}$ Jacqueline Dussaillant, Breve historia de los avisos publicitarios en los principales periódicos chilenos, 1850-1920, tesis para optar al grado de Licenciada en Historia, Santiago, Pontificia Universidad Católica de Chile, 1992, p. 152; Álvarez, op. cit., p. 59.
} 
no al Halley para ofrecer sus productos en la prensa, como quedó evidenciado con la zapatería "Los Negros" -ubicada en Alameda 2890, cerca de la Estación Central- la que anunció una oferta en El Diario Ilustrado de la siguiente manera (fig. 6):

"Por comunicación directa de un observatorio de Europa, queda ya como hecho que va a realizarse el choque de la tierra con el cometa Halley. [...], nos es, aunque muy sensible, comunicar a todo Santiago, para que con su debido tiempo se prevea de todos los artículos necesarios para un tan largo viaje al otro mundo, acudiendo en primer lugar a comprar su rico calzado en la Gran Fábrica de Los Negros [...]"116.

FiguRA 4

"Té Horniman" (1909)

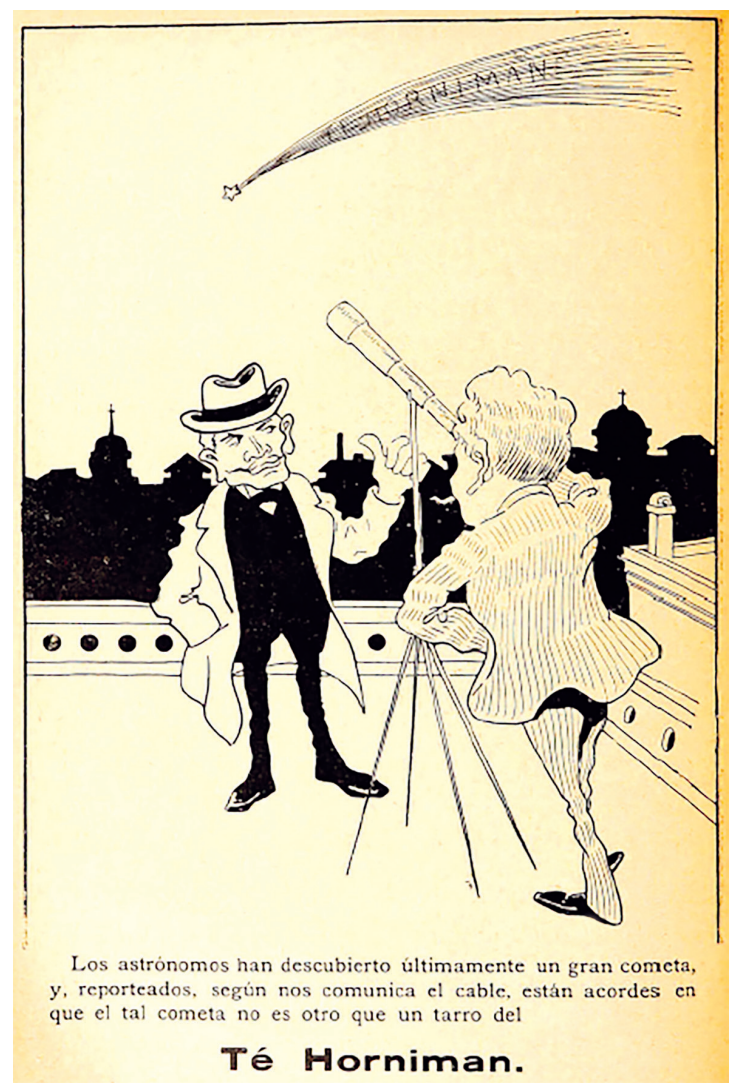

Fuente: Sucesos, n. ${ }^{\circ}$ 375, Valparaíso, 18 de noviembre de 1909, $\mathrm{s} / \mathrm{p}$.

116 "El Mundo se acaba. Encuentro de la Tierra con el cometa Halley", en El Diario Ilustrado, Santiago, 3 de abril de 1910, p. 1. 
Figura 5

"Aceite Escudo Chileno"

(1910)

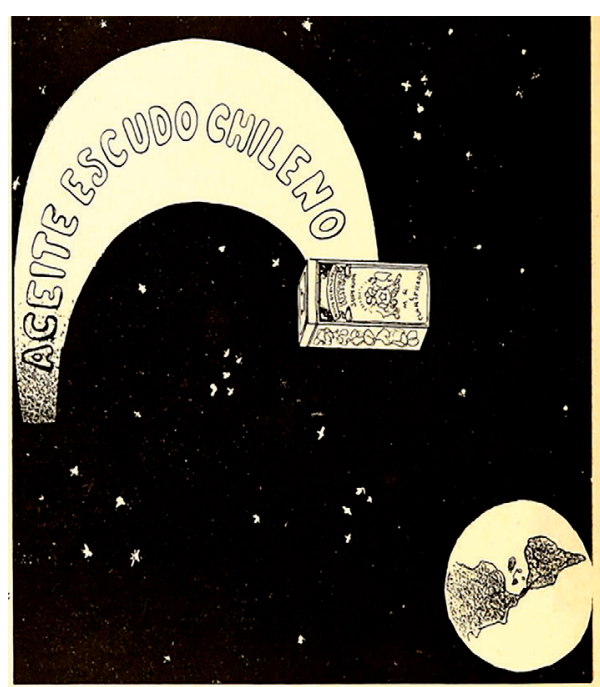

Unioss lunportatores Ferro Sanguinetti y Cía. VALPARAISO

Fuente: Sucesos, n. ${ }^{\circ} 392$, Valparaíso, 10 de marzo de $1910, \mathrm{~s} / \mathrm{p}$.
FIGURA 6

Calzados "Los negros"

(1910)

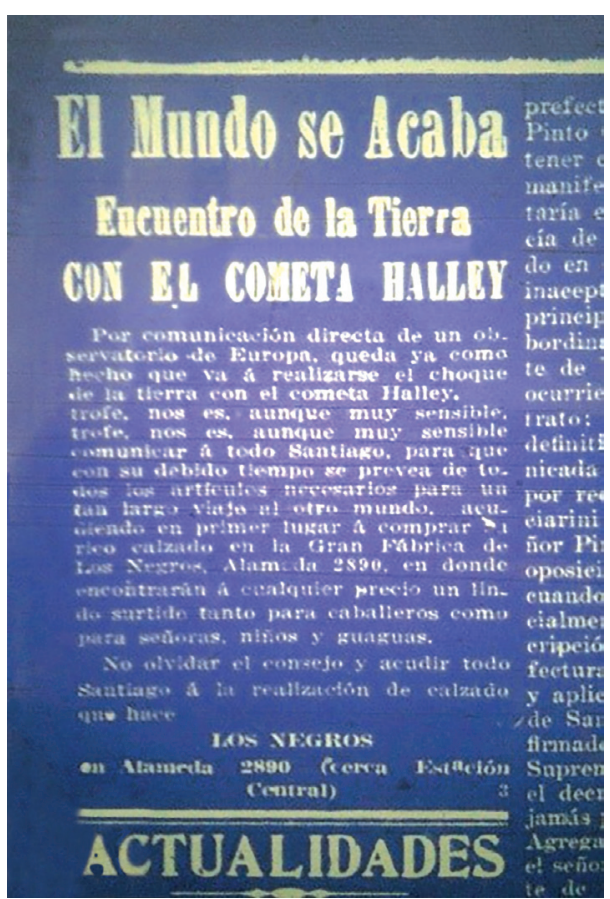

Fuente: "El Mundo se Acaba. Encuentro de la Tierra con el Cometa Halley", en El Diario Ilustrado, Santiago, 3 de abril de 1910, p. 1. 
Figura 7

"Té Dulcinea"

(1910)

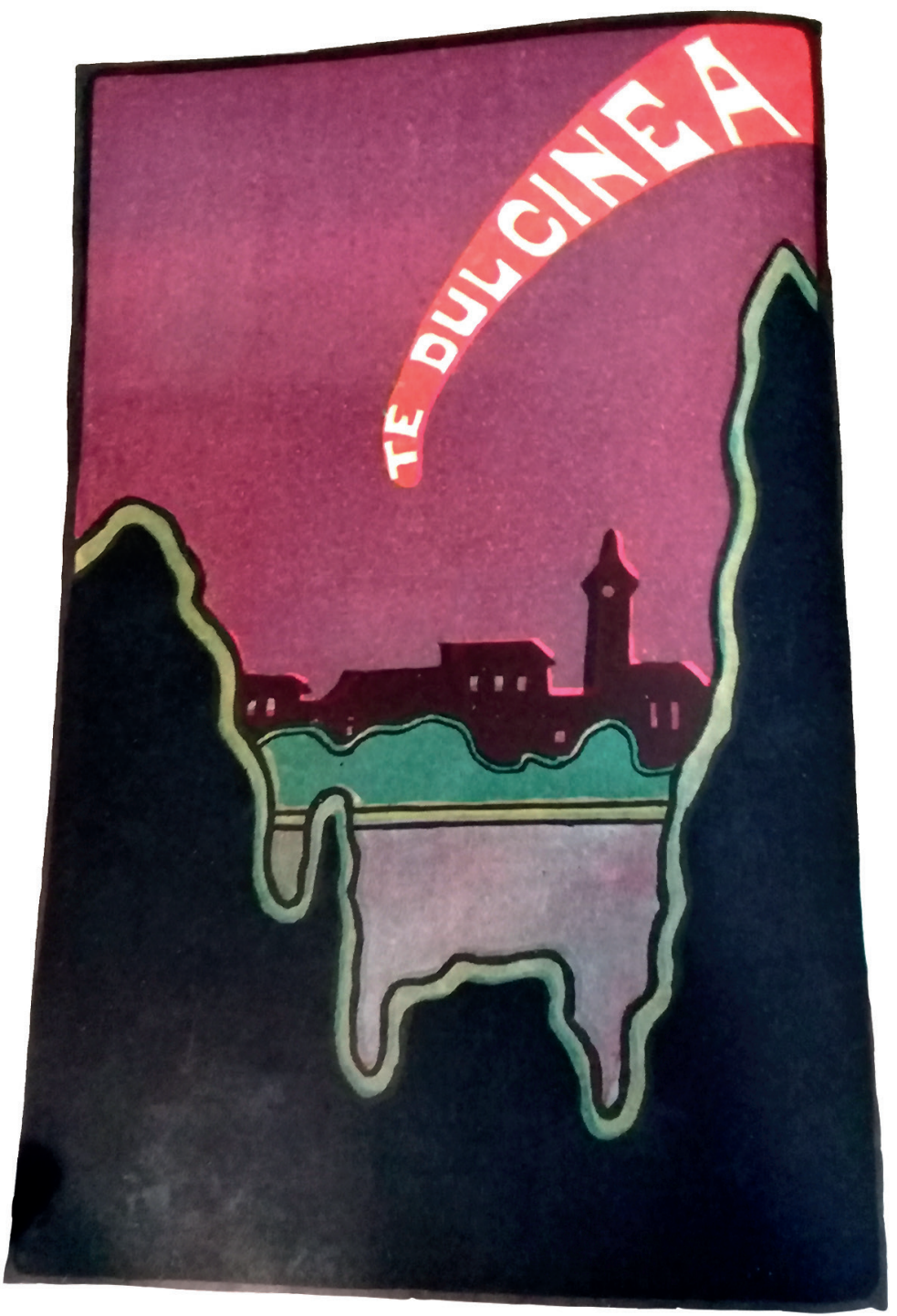

Fuente: Corre-Vuela, s/n. ${ }^{\circ}$, Santiago, 4 de mayo de 1910, s/p.

Junto a esto, el atractivo de las audiencias por el inminente paso del Halley coincidió, también, con el aumento en estos medios de la incorporación de obras literarias vinculadas a fenómenos de este tipo, como puede verse en el siguiente cuadro: 


\begin{tabular}{|l|l|c|c|c|}
\hline \multicolumn{1}{|c|}{ Título } & \multicolumn{1}{c|}{ Autor } & Género & Medio & Año \\
\hline El fin del mundo & Camille Flammarion & Narrativa & Zig-Zag & 1905 \\
\hline El llamado de otro mundo & Sin firma & Narrativa & Zig-Zag & 1907 \\
\hline Los habitantes de Júpiter & Sin firma & Narrativa & Sucesos & 1908 \\
\hline Comunicaciones con el planeta Marte & Sin firma & Narrativa & Sucesos & 1908 \\
\hline Un viaje a otros mundos & Sin firma & Narrativa & Zig-Zag & 1909 \\
\hline ¡Ya viene! & Antuco Antúnez & Poema & Zig-Zag & 1910 \\
\hline Luminar del éter & Juan Ramón Molina ${ }^{118}$ & Poema & Zig-Zag & 1910 \\
\hline Carta del Cometa Halley & ${\text { J. M. R. }{ }^{119}}^{119}$ & Poema & Sucesos & 1910 \\
\hline Esperando el Cometa & Misael Guerra P. ${ }^{120}$ & Narrativa & Diario & 1910 \\
\hline De otros días & & & Ilustrado & 1910 \\
\hline Diana y Eros: Un cuento astronómico & Amado Nervo ${ }^{122}$ & Narrativa & Sucesos & 1911 \\
\hline
\end{tabular}

La presunta colisión del Halley con la Tierra generó expectación en los lectores de estas publicaciones, quienes, ante la necesidad de información fidedigna, comenzaron a manifestar sus dudas e incertidumbres a los directores de los periódicos y revistas nacionales. Un ejemplo de esto se encuentra en la sección de "Preguntas y respuestas" de revista Zig-Zag, en la que se publicaban consultas de los lectores dirigidas al director del magazine. Así, frente a la pregunta de una lectora sobre el supuesto fin del mundo que causaría el cometa Halley, el director de Zig-Zag respondió: "Con toda franqueza, señora, tengo el gusto de decir a usted que el 18 de Mayo no se concluirá el mundo, y (como hoy es el 20) ya está usted segura de que lo que le digo es la pura verdad"123. Este tipo de ejemplos demuestra que sí hubo una demanda de noticias sobre el cometa por parte de la población chilena en la época.

El Halley en Chile, al igual que en otros lugares del mundo, se convirtió en un producto comercial que fue explotado de las más diversas maneras. Esta práctica, sin embargo, se adscribió a lo que ya era común en aquel entonces; nos referimos al tratamiento de lo científico como negocio y mercancía ${ }^{124}$. Como señalan Aileen Fyfe y Bernard Lightman, los cambios culturales vinculados a la ciencia no solo repercutieron en las élites científicas, sino, también, y sobre todo en sus audiencias ${ }^{125}$. Estas últimas comen-

${ }^{117}$ Antuco Antúnez es el seudónimo del escritor y periodista chileno Pedro Gil y Rosas (1875-1934). Su estilo en medios periodísticos destacó por el humor y la crítica satírica.

118 Juan Ramón Molina (1875-1908) fue uno de los poetas hondureños más reconocidos universalmente en la época. Se destacó como uno de los grandes exponentes del Modernismo en Centroamérica y dejó huellas en varios países de Latinoamérica.

${ }^{119}$ No hemos podido identificar a quién pertenecen estas iniciales, aunque creemos que pueden corresponder al poeta hondureño Juan Ramón Molina, cuyas iniciales se habrían escrito desordenadas por error.

${ }^{120}$ Seudónimo del chileno Ismael Parraguez (1883-1917), quien fue profesor normalista, músico y escritor.

${ }^{121}$ Solo sabemos de este autor que además de colaborar en revista Corre-Vuela también lo hizo en Sucesos.

${ }^{122}$ Amado Ruiz de Nervo (1870-1919), destacado escritor mexicano perteneciente al movimiento modernista. Colaboró en diversos periódicos de la época.

123 "Preguntas y Respuestas", en Zig-Zag, n. ${ }^{\circ}$ 274, Santiago, 21 de mayo de 1910, s/p.

${ }^{124}$ Nieto-Galan, Los públicos..., op. cit., p. 66.

${ }^{125}$ Fyfe y Lightman, op. cit., p. 4. 
zaron a verse a sí mismas como consumidores, ya sea de libros, de museos y de distintas prácticas científicas. Estas audiencias, no obstante, no pueden entenderse como simples receptores pasivos del conocimiento, tal como lo defienden James Secord (2004) y Jürgen Renn (2015), ya que el consumidor escoge y, en este caso particular, selecciona entre las fuentes disponibles para formular su propia amalgama de conocimientos sobre el mundo natural ${ }^{126}$. Los impulsores de la industria editorial, quienes también forman parte de los llamados públicos de la ciencia, comprendieron rápidamente la oportunidad que existía detrás de este proceso cultural y se sirvieron de ello para sostener sus propios negocios. A esto último se debe agregar que en Chile el inicio del siglo XX trajo consigo la modernización de esta industria, en especial la producción de prensa diaria, periódicos y revistas de distribución masiva, cuyos propósitos dieron un evidente giro hacia fines comerciales ${ }^{127}$. La prensa en este contexto fue un medio que pudo acoger múltiples intereses asociados a lo científico, tales como la necesidad de legitimación de las instituciones y de los expertos, el deseo de informarse y entretenerse de parte de los lectores, y el propósito económico de los proyectos periodísticos, entre otros.

Además de los productos editoriales ya mencionados, se deben considerar también los almanaques, que según Bernardo Subercaseaux correspondieron a un quinto de las impresiones de libros y folletos que se publicaron a principios del siglo XX en Chile ${ }^{128}$. El Observatorio Astronómico Nacional editó en noviembre de 1909 el primer Almanaque astronómico de Chile dedicado al calendario del año 1910. Como precisó el director del OAN en su prefacio, este almanaque, a diferencia de otros, prescindía de asuntos astrológicos y pasatiempos, así como de extensas alusiones sobre festividades y actos civiles, y se atenía a cuestiones centradas en lo astronómico, pero presentadas para un público amplio, como aquí se lee:

"Este libro [...] está destinado a servir a la Marina Chilena, que en casi todos los casos que se ofrecen no necesita las grandes y voluminosas efemérides; a servir para la enseñanza a los profesores de Liceos y también de las Escuelas Primarias; a los oficiales del Ejército; a los agricultores para la división de su día de trabajo y para encontrar las direcciones del horizonte; y en fin, a cada persona culta que recuerde que toda nuestra vida depende del Sol y de las estrellas, no en el sentido de los astrólogos [...]"129.

En palabras del mismo astrónomo, el almanaque del OAN salió a la luz en el momento en que Chile se encontraba reorganizando su Observatorio, idea que el director enlazó con la relevancia del trabajo de esta institución, al señalar que una publicación como esta, producida por el personal del OAN, ayudaría a "labrar el progreso de la patria"130.

\footnotetext{
${ }^{126}$ Fyfe y Lightman, op. cit., p. 4.

${ }^{127}$ Ossandón y Santa Cruz, op. cit., p. 118.

${ }^{128}$ Bernardo Subercaseaux, Historia del libro en Chile (alma y cuerpo), Santiago, Editorial Andrés Bello, 1993, p. 97.

${ }^{129}$ Federico Ristenpart, Almanaque astronómico de Chile, Santiago, Imprenta de la Oficina del Tiempo, 1909, p. iii.

${ }^{130}$ Ristenpart, op. cit., p. iv.
} 
Por último, hay que mencionar la oferta de libros científicos en el país. En la primera década del siglo XX existían en Santiago más de cuarenta librerías, las que ofrecían obras con títulos y temáticas variadas, destinadas a un público amplio conformado por distintos estratos sociales ${ }^{131}$. Tal como afirma Bernardo Subercaseaux, a fines del siglo XIX se produjeron algunos cambios que activaron la circulación y comercialización de libros en el país, tales como la modernización y especialización de algunas librerías, el interés del Estado sobre el acceso a los libros y el aumento de puntos de venta de estos $^{132}$. La Librería Inglesa, a fines del siglo XIX, ofrecía libros en inglés, casi todos vinculados a la enseñanza técnica y profesional; mientras que la Librería Miranda promocionaba libros importados sobre metalurgia, mineralogía, astronomía, topografía, electricidad, matemáticas y ciencias naturales ${ }^{133}$. Esta tendencia comercial se debió a una proyección de la modernización y del ambiente cientificista prevaleciente ${ }^{134}$, que en el año 1910 se abocó, entre otros fenómenos científicos, al cometa Halley.

Es importante señalar que durante el mismo periodo las librerías chilenas ofrecieron los siguientes libros de Camille Flammarion: Elementos de astronomía; Estela; Urania; Los mundos imaginarios y los mundos reales; Viajes aéreos y El fin del mundo, entre otros $^{135}$. Además, la Biblioteca Nacional adquirió algunos textos del astrónomo francés para ser consultados por el público general ${ }^{136}$. Esto nos indica que Camille Flammarion ya era conocido en el país y que ya existía un mercado de libros de su autoría previo a 1910, lo que permitió sembrar las bases para que con el paso del Halley y, sobre todo, con la hipótesis de la peligrosidad de este astro, se impulsara un fenómeno editorial que se extendió más allá de los libros, abarcando gran parte de la industria periodística.

\section{CONCLUSIÓN}

A través de un marco teórico cuya perspectiva principal considera a la historia de la ciencia, concentrada, sobre todo, en la relevancia de los públicos, se analizaron diversos materiales impresos publicados en Chile en el periodo estudiado, tales como periódicos, revistas, almanaques, libros, etc., referentes al paso del cometa Halley de 1910.

El análisis reveló que la circulación de las predicciones científicas que atribuían un carácter peligroso al Halley contribuyó a generar una oportunidad para conseguir legitimación de parte de algunas autoridades científicas locales, en especial de Friedrich Ristenpart, director del Observatorio Astronómico Nacional durante esos años. La difusión de la supuesta toxicidad de la cola del cometa ofreció a este astrónomo alemán un escenario propicio para exponer sus propias observaciones, publicitando una imagen

${ }^{131}$ Cornejo, op. cit., pp. 367-371.

${ }^{132}$ Subercaseaux, op. cit., p. 103.

133 Ibid.

${ }^{134}$ Ibid.

${ }^{135}$ Catálogo jeneral de la Librería de Roberto Miranda, Santiago, Imprenta y Encuadernación del Comercio, 1902, p. 139; Catálogo de la Librería C. Tornero y Ca., Santiago, Imprenta de la Librería C. Tornero y Ca., 1904, p. 6; Catálogo escolar de la Librería Alemana, Santiago, Imprenta del Universo, 1901, p. 8.

${ }^{136}$ Boletín de la Biblioteca Nacional, n. ${ }^{\circ}$ 11, Santiago, 1902, p. 203. 
renovada de la institución científica chilena como una que aportaba al desarrollo de la ciencia y al progreso del país. No obstante, como ya se explicó, ese contexto no habría sido conveniente para dicha causa si no se hubiesen manifestado con persistencia ciertas hipótesis alarmistas alimentadas por la prensa y transmitidas con tono sensacionalista. Tampoco habría sido posible sin las condiciones culturales, científicas y tecnológicas del periodo.

La reciente implementación del análisis espectroscópico y sus incipientes aplicaciones, por ejemplo, todavía dejaba vacíos que abrían puertas a la especulación sobre la composición de los astros. Lo mismo se puede decir con respecto a la fácil observación que ofrecía el cometa dispuesto a las miradas de todo público, sin necesidad de utilizar un instrumento. Este ambiente posibilitó la instalación de una discusión científica en 1910 que solo fue posible gracias a las múltiples particularidades de la época, y que contribuyó para que una figura como la de Ristenpart pudiera encontrar una vía a su alcance para intentar conseguir legitimación como autoridad científica dentro de la sociedad y mejorar la imagen de la institución que lideraba.

El fenómeno anterior recibió un fuerte impulso, sin duda, gracias a la activación de un mercado editorial en torno al cometa de 1910. Sin esta condición, la búsqueda de legitimación de expertos y la consolidación de audiencias no se habrían activado. Por lo que la modernización de la industria editorial y la visualización que de sí mismos tuvieron los públicos como consumidores, ayudaron significativamente para que el Halley fuera, por una parte, explotado como un objeto comercial y, por otra, utilizado para intentar certificar la experiencia de la autoridad astronómica en el país. 